\title{
UNA MACRO-ALDEA EN EL ORIGEN DEL MODO DE VIDA CAMPESINO: MARROQUÍES BAJOS (JAÉN) C. 2500-2000 cal. ANE
}

\author{
A MACRO-VILLAGE AS THE ORIGIN \\ OF THE PEASANT WAY OF LIFE: \\ MARROQUÍES BAJOS (JAÉN, SPAIN) \\ c. 2500-2000 cal. BC
}

\author{
NARCISO ZAFRA DE LA TORRE $(*)$ \\ FRANCISCA HORNOS MATA (*) \\ MARCELO CASTRO LÓPEZ (*)
}

\begin{abstract}
RESUMEN
Se presenta una aproximación a los tiempos y formas de un asentamiento altoandaluz de la Edad del Cobre que ocupa al menos 113 hectáreas. Las extensas excavaciones realizadas revelan una división entre el espacio de hábitat y los campos. En su fase de mayor extensión estaba organizado en coronas definidas por fosos concéntricos excavados en la roca, 4 intramuros y 1 al exterior de la muralla. El espacio de hábitat (34 has.) está rodeado por una muralla de adobe de $3 \mathrm{~m}$. de altura y unos $2 \mathrm{~km}$. de perímetro, bordeada por un foso de profundidad variable (2-5 m.) y anchura irregular (6-10 m.). El foso localizado en los campos podría tener un diámetro máximo de $1200 \mathrm{~m}$. Aquí nos limitaremos a exponer las primeras hipótesis sobre formación y evolución del sitio, empezando por su cronología, periodización y fases, para finalizar con los mecanismos que rigen en los procesos de cambio de sus estructuras sociales. La escala de la investigación (intra-sitio) hace que se preste especial atención a las formas, funciones y relaciones de las unidades domésticas, interpretando su evolución como un proceso de intensificación agraria que desemboca en la institucionalización de las unidades domésticas campesinas ( familia + tierra = casa) como célula social de producciónreproducción.
\end{abstract}

(*) Consejería de Cultura de la Junta de Andalucía. Delegación Provincial de Jaén. Martínez Montañéz 8, 23007 Jaén. Correo electrónico: fhm@mx3.redestb.es

El artículo fue remitido en su versión final el 28-I-1999.

\begin{abstract}
An approach is presented to the chronology and form of a high-Andalusian settlement from the Copper Age which occupies at least 113 hectares. The extensive excavations show a division between the habitation area and the fields. In its stage of greatest expansion it was organized in circlets defined by concentric ditches excavated in the rock, 4 inside the wall and 1 outside. The habitat area (34 has) is surrounded by a $2 \mathrm{~km}$ long and 3 metres high wall built with adobe, and it is bordered by a ditch of variable depth $(2-5 \mathrm{~m}$.) and irregular width $(6-10 \mathrm{~m}$.). The ditch found in the fields may have a maximum diameter of 1200 metres. Here we will just set forth the first hypotheses on the formation and evolution of the site, beginning with its chronology, periodization and phases, and finishing with the mechanisms which govern the processes of change in social structure. The research scale (intra-site) makes it possible to pay special attention to the forms, functions and relations of the domestic units, interpreting the site's evolution as a process of agrarian intensification which results in the institutionalisation of the peasant domestic units (family + land = household) as a social cell of production-reproduction.
\end{abstract}

Palabras clave: AltaAndalucía. Edad del Cobre. Edad del Bronce. Regadío. Relaciones de propiedad. Campesinado. Paisaje agrario. Arqueología urbana.

Key words: High Andalusia. Copper Age. Bronze Age. Irrigation land. Property relations. Peasantry. Agrarian landscape. Urban archaeology. 


\section{INTRODUCCIÓN}

Publicar, difundir, dar a conocer los resultados es una obligación básica para los equipos de investigación. Primero porque hace público lo que se obtiene en nombre de un interés social (con fondos públicos o privados) y segundo porque lo publicado es algo siempre discutible y sobre todo utilizable.

No es aquí donde insistiremos en la problemática de la Arqueología Urbana o la Arqueología Comercial pero es conveniente saber que es esa dinámica la que está dando lugar a un gran avance en la investigación sobre diversas fases culturales que son el objetivo de conocimiento para la disciplina arqueológica.

En la actualidad creemos que no es exagerado afirmar que los programas de investigación arqueológica dependen fundamentalmente de esta vía de financiación, al menos en nuestro entorno. Prácticamente todo lo que aquí diremos y lo que hemos dicho antes de este sitio se sostiene en una financiación de la investigación que proviene de aplicar una legislación coercitiva sobre los agentes implicados en la dinámica urbanística de las ciudades actuales (Hornos et alii, 1998). Por lo tanto, no debemos olvidar que se basa en la aplicación de una norma y no en un consenso. Es decir, las tensiones que se originan en estas prácticas provienen de su rareza en el momento actual donde casi nada se impone y todo, absolutamente todo, es posible pactarlo. En lo que se refiere a la protección del patrimonio arqueológico no es así, al menos no en este caso, porque aquí se ha aplicado un formato legal, que no es compartido por los implicados aunque sí acatado e inmediatamente recurrido por las vías legales que un Estado democrático debe garantizar a todos sus ciudadanos. Conviene presentar los hechos con claridad, para evitar sorpresas indeseadas y explicaciones indeseables. La legislación garantiza la protección del patrimonio histórico pero también garantiza los derechos económicos de los agentes implicados en la edificación de nuestras ciudades.

El objetivo de este texto es proponer respuestas a las preguntas que surgieron durante el trabajo concreto de investigación de una zona urbana-urbanizable con evidencias contrastadas de interés arqueológico, las respuestas y nuevas preguntas se van conformando según avanzan los trabajos de documentación. La delimitación de la zona y el control de las intervenciones que se están realizando en el lugar nos han llevado a establecer, desde abril de 1995, protocolos de control para aunar los criterios

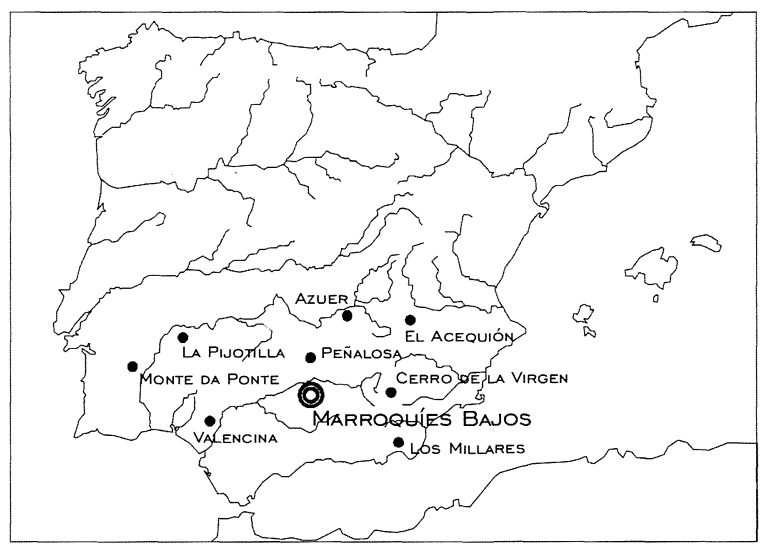

Fig. 1. Localización de los asentamientos mencionados en el texto.

que necesariamente hemos de manejar para tomar decisiones sobre el futuro.

La relación entre investigación y protección se muestra en el caso de la Zona Arqueológica de Marroquíes Bajos (ZAMB) ( Fig. 1) con una constante intensidad. La situación de pérdida del patrimonio arqueológico es una situación habitual para las personas que precisamente nos ocupamos dentro de Instituciones Culturales de prevenirla, evitarla y si esto no es posible, paliarla. Por eso lo mas significativo de este sitio no es, ni lo ha sido nunca, la pérdida de patrimonio arqueológico en sus dos vertientes (información y materialidad). Desapariciones-destrucciones incontroladas sigue habiendo y desde el momento en que no las conocemos son, como pérdidas, mucho mas importantes que la del caso que nos ocupa.

De cualquier manera, los últimos cuatro años han significado una concentración de recursos de investigación sobre la Zona Arqueológica de Marroquíes Bajos como no ha habido otra en el territorio de nuestra provincia. El efecto primero de la protección ha sido la posibilidad de la investigación, después han venido el aumento del conocimiento y la necesidad de profundizar y establecer estrategias de planificación para aprovechar la información obtenida. Hoy por hoy (octubre 1998) estamos en condiciones de encauzar esa actividad en el marco de las actividades investigadoras de una Institución específica de investigación arqueológica, el Centro Andaluz de Arqueología Ibérica de la Universidad de Jaén y a partir de este hecho la formulación del Programa de Investigación de la Zona Arqueológica de Marroquíes Bajos se transforma, adquiere otra tonalidad y sobre todo otro ritmo.

T. P., 56, n. ${ }^{\circ} 1,1999$ 
El texto que aquí presentamos es la última mirada sobre el sitio arqueológico desde el planteamiento de la investigación "urgente" y necesariamente "sintética". A partir de este momento se abre una nueva etapa para el sitio y su futuro de zona musealizada y/o de centro de documentación. Es el momento de la construcción de teorías, de la formalización de los datos, de ir presentando parcialmente los estudios que ya están iniciados o de rebatir o refutar lo ya presentado. También es el momento de pensar en los usuarios potenciales de ese patrimonio arqueológico que hemos podido arrebatar a su destino de destrucción porque esos restos materiales no están listos para ser comprendidos y es preciso concentrar recursos materiales y humanos en un esfuerzo de interpretación de la ZonaArqueológica que la haga comprensible.

En el sitio se han realizado desde 1995 unas 100 excavaciones arqueológicas. La tabla 1 contiene la relación de intervenciones realizadas, sus directores y las entidades financiadoras. Los informes previos inéditos se encuentran en elArchivo de la Delegación Provincial de la Consejería de Cultura en Jaén a disposición de los investigadores que trabajan en el lugar.

\section{LA ZONA ARQUEOLÓGICA DE MARROQUÍES BAJOS}

Jaén es una ciudad de piedemonte construida de espaldas a la montaña y abierta al norte hacia la campiña (Lám. I). Tradicionalmente se ha articulado en tres espacios bien diferenciados el Cerro de Santa Catalina dominado por el castillo, la ladera norte cercada por la muralla romana y medieval y

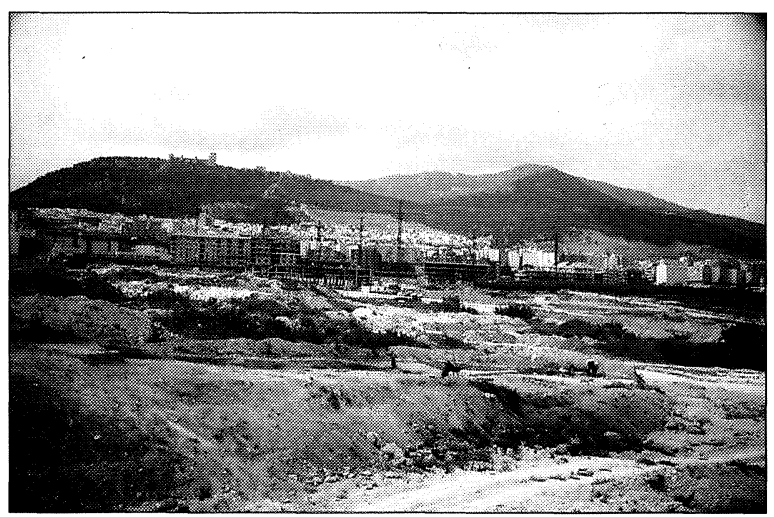

Lám. I. Jaén vista desde el Norte. En primer plano Marroquíes Bajos. Fotografía M. Castro (Archivo de la Delegación Provincial de Jaén). las tierras bajas con áreas extensas de huertas que aprovechaban el abundante caudal proveniente de los niveles freáticos del interior de la ciudad. Marroquíes Bajos ocupa una importante porción de las áreas bajas (Fig. 2).

$\mathrm{Su}$ aspecto previo a la urbanización era fruto de la superposición de diferentes comunidades que durante al menos 4500 años, habitaron y explotaron el territorio, dejando potentes huellas materiales de su paso. La ocupación está permanentemente orientada a la explotación de los recursos agrícolas y al desarrollo de las técnicas hidrogógicas necesarias para su aprovechamiento intensivo. Los sistemas de canalización se suceden en el tiempo y bajo las acequias aún en funcionamiento se han localizado drenajes del siglo XVII; atarjeas, canales y molinos de noria islámicos; molinos, albercas y canales romanos; y soportándolo todo el gran sistema hidráulico prehistórico que continúa hasta hoy decidiendo sobre las trayectorias de las aguas subterráneas en la zona.

La investigación extensiva ha proporcionado una visión de conjunto poco frecuente que posibilita el reconocimiento de sucesivos modos de ordenación del espacio. Esa nueva perspectiva ha roto la mecánica convencional de registro, ha variado la escala de inferencia inmediata. No es infrecuente fechar arroyos o delimitar barrancos y se han excavado, junto con las áreas de habitación, grandes superficies de tierras de cultivo. Ya se empieza a reconocer el parcelario fósil de época romana y la trama urbana de uno de los asentamientos islámicos. Es de destacar que esta escala de trabajo impone a la arqueología urbana nuevas respuestas metodológicas, somos conscientes de que no estamos investigando en un "yacimiento" (1) al uso (un área construida mas o menos compleja) sino que estamos levantando por capas un paisaje que ha sido esculpido a lo largo de casi 5000 años por un cúmulo de comunidades que lo han adaptado a sus necesidades.

Ese proceso de tiempo largo ha sido jalonado por hitos que marcan las grandes transformaciones del sitio, y que se pueden rastrear en las modificaciones paleomorfológicas de los sucesivos agrosistemas. El reconocimiento de esos hitos va asociado a la detección y delimitación de las grandes infraestructuras que vertebran el poblamiento. La intensificación planificada de la agricultura que parece señalar el sistema hidrogógico prehistórico, la par-

(1) El término "yacimiento" que margina a las áreas no construidas de los territorios se ha sustituido sistemáticamente por "zona arqueológica" que no presenta connotaciones extractivas. 


\begin{tabular}{|c|c|c|}
\hline MANZANA-PARCELA & DIRECTORAA ACTMDAD ARQUEOLÓGICA, AÑOS DURACIÓN & ENTIDADES FINANCIADORAS DE LA INVESTIGACIÓN \\
\hline SECTOR URBANISTICO & \multicolumn{2}{|l|}{ RESIDENCIAL PROGRAMADO No 4 (RP 4) } \\
\hline A $15-J, A 3, A 4$ & $\begin{array}{l}\text { PENEDO COBO, 1996; LIZCANO PRESTEL, 1997; BARBA } \\
\text { COLMENERO,V.,1998 }\end{array}$ & COVALMONY OTROS; GECOSUR; DOYMA JAÉN S.L. \\
\hline$B 16, B 1$ & MAJOR GONZÁLEZ, 1996, 1997; ZAFRA SÁNCHEZ, 1998,1999 & MARTINEZ VZCAINO; GECOSUR \\
\hline D2,D3 D4,D5 & $\begin{array}{l}\text { MARTÍNEZ OCAÑA, 1996,1997; PÉREZ BAREAS,C., 1997; } \\
\text { BURGOS JUÁREZ, 1997,1998 }\end{array}$ & $\begin{array}{l}\text { HIERROS SERRANO GÁMEZ Y OTROS: ESTACIÓN NORTE S.L.; } \\
\text { MORALES VDA Y OTROS C.B. }\end{array}$ \\
\hline E & $\begin{array}{l}\text { MOYA GARCIA,S.,1995; SERRANO PEÑA,J.L.,1996, 1997; } \\
\text { SERRANO PEÑA,J.L.,1998 }\end{array}$ & CONSEJERIA DE CULTURA: INDUSTRIAS EL ANGEL-EDISUR : \\
\hline $\begin{array}{l}\mathrm{FI}, \mathrm{F} 2, \mathrm{~F} 3, \mathrm{~F}-25, \mathrm{~F} \\
\text { BORDE ORIENTAL }\end{array}$ & $\begin{array}{l}\text { ZAFRA SÁNCHEZ, 1996, 1997; LIEBANASY } \\
\text { LLORENTE,1996, 1997; LIZCANO PRESTEL Y OTROS, 1997; } \\
\text { CASTRO LÓPEZ Y OTROS, } 1998\end{array}$ & CONSEJERÍA DE CULTURA; ECUS 3,S.L; COVALMON \\
\hline $\begin{array}{l}\text { G1,G2,G3,G4,G5 } \\
\text { G23-24 }\end{array}$ & 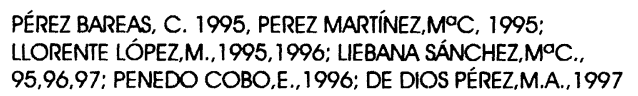 & $\begin{array}{l}\text { CONSEJERÍA DE CULTURA: SCA DE VMENDAS DE ENFERMERIA; } \\
\text { COVALMON; EDISUR }\end{array}$ \\
\hline $\mathrm{H} 1, \mathrm{H} 2$ & PENEDO COBO,E.,1997,1998, 1999 & $\begin{array}{l}\text { CONSEJERIA DE CULTURA (PROPUESTA); HIERROS SERRANO } \\
\text { GAMEZ, URBAIN, ANDALUZA DE GESTIÓN }\end{array}$ \\
\hline I B-1,I NORTE,124 & DE DIOS PÉREZ, 1996, 1997,1998; LIZCANO PRESTEL 1998 & $\begin{array}{l}\text { URBAIN C.B,HOGARJI S.L.,PROVSA: MÁRMOLES MARMESA: } \\
\text { ARCASA: }\end{array}$ \\
\hline J 16-A,J1,J36 & $\begin{array}{l}\text { SERRANO PEÑA, J.,1996,1997: ZAFRA SÁNCHEZ, J.,1997; } \\
\text { LIZCANO PRESTEL, R.,1998 }\end{array}$ & $\begin{array}{l}\text { URBAINSA. HOGARJI S.L.; ECUS } 3 \text { S.L.; INDUSTRIAS EL } \\
\text { ANGEL,EDISUR; }\end{array}$ \\
\hline $\mathrm{K}, \mathrm{K} 45$ & PENEDO COBO,E.,1996.1997; MONTILLA PÉREZ,I.,1997,1998 & $\begin{array}{l}\text { NOAJA,COOPERATNA DE CONSTRUCCIONES; MELERO } \\
\text { CABALLERO,F.YR. }\end{array}$ \\
\hline $\begin{array}{l}\text { OBRAS DE } \\
\text { URBANIZACIÓNE } \\
\text { INFRAESTRUCTURAS }\end{array}$ & PÉREZ MARTÍNEZ,MํC. Y OTROS, 1996,1997,1998,1999 & AYUNTAMIENTO DE JAÉN \\
\hline SECTOR URBANISTICO & SUELO URBANIZABLE NO PROGRAMADO No 1 & \\
\hline $\begin{array}{l}\text { URBANIZACIÓNE } \\
\text { INFRAESTRUCTURAS }\end{array}$ & $\begin{array}{l}\text { CANO CARRILLO, J., 1996,1997:SERRANO PEÑA } \\
\text { J.L.,1997,1998,1999 }\end{array}$ & EPSA \\
\hline SECTOR URBANISTICO & UNIDAD DE ACTUACIÓN No 23 & \\
\hline $\begin{array}{l}A 1, A 2, A 4, A 5, A 6, A 7 Y \\
A 8\end{array}$ & $\begin{array}{l}\text { MOYA GARCIAA.S., 1995,1997; BURGOS JUÁREZ, A., 1996; } \\
\text { CANO CARRILLO, J.,1996,1997; LIZCANO PRESTEL, R.,1997; } \\
\text { PUERTA TORRALBO, D.,1998 }\end{array}$ & $\begin{array}{l}\text { CONSEJERÍA DE CULTURA: IBÉRICA OSUNA, S.A.; TISCARY } \\
\text { OTROS }\end{array}$ \\
\hline $\begin{array}{l}\text { B1,B2,B3,B4,B9-1,B9- } \\
3, B 10, B 11, A P A X Y 1\end{array}$ & $\begin{array}{l}\text { ROYO ENCARNACIÓN,MA., 1995; LIZCANO PRESTEL, R., } \\
\text { 1995; ZAFRA SÁNCHEZ, J.1995; CANO CARRILLO,J.,1995; } \\
\text { SANGUINO VÁZQUEZ, J.,1996,1997; RUS DE LA RUBIA.E.,1996; } \\
\text { MOYA GARCÍA.S.,1995,1997; PÉREZ MARTÍNEZ,MC.,1996; } \\
\text { MARTÍNEZ OCAÑA. J.L.,1998 }\end{array}$ & $\begin{array}{l}\text { CONSEJERIA DE CULTURA: COVIAÉN, S.C.A.; URBAINSAY Y } \\
\text { HOGARJI; VALDERRAMA PROMOCIONES; AYUNTAMIENTO DE } \\
\text { JAÉN }\end{array}$ \\
\hline $\mathrm{C} 3, \mathrm{C} 4$ & ZAFRA SÁNCHEZ,J., 1995; LIZCANO PRESTEL, 1995 & CONSEJERÍA DE CULTURA: VALDERRAMA PROMOCIONES \\
\hline DI,D4,D5 & ZAFRA SÁNCHEZ,J., 1995; LIZCANO PRESTEL,R., 1995 & CONSEJERÍA DE CULTURA: HJOS. DE JUAN DELGADO \\
\hline $\begin{array}{l}\text { E1,E3,E2-1,E2-2,E2- } \\
4, E 2-5, E 2-6\end{array}$ & $\begin{array}{l}\text { CANO CARRILLO, J. 1995; ROYO } \\
\text { ENCARNACIÓN,MA 95,96,97; MOYA GARCÍA, S.,1995,1997; } \\
\text { PÉREZ BAREAS,C.1995,1996; ZAFRA DE LA TORRE,N.,1996; } \\
\text { SANGUINO VÁZQUEZ, J.,1997; BARBA COLMENERO,V,1998 }\end{array}$ & $\begin{array}{l}\text { CONSEJERIA DE CULTURA: VALDERRAMA PROMOCIONES; } \\
\text { INMOBILLARIA ALCAUDETENSE; SOMUMSA }\end{array}$ \\
\hline $\begin{array}{l}\text { INFRAESTRUCTURASY } \\
\text { URBANIZACIÓN }\end{array}$ & LIZCANO PRESTEL, R. , 1995: BURGOS JUÁREZ, A. 1997 & CONSEJERÍA DE CULTURA: JUNTA DE COMPENSACIÓN \\
\hline SECTOR URBANÍSTICO & UNIDAD DE ACTUACIÓN No 25 & \\
\hline $\begin{array}{l}\text { A,B,CY VALES } \\
1,2,3,4,5,6,7, B 2\end{array}$ & BURGOS JUÁREZ,A., 1998; ROYO ENCARNACIÓN,MA., 1998 & JUNTA DE COMPENSACIÓN DE LA UA 25; SOMUMSA \\
\hline
\end{tabular}

Tab. 1. Actividades arqueológicas realizadas en Marroquíes Bajos.

T. P., 56, n. ${ }^{\circ} 1,1999$ 
celación lineal romana con su retícula de canales y acequias o la urbanización de áreas de cultivo por encima de la cota 485 en época islámica son tres impactos notables sobre el paisaje, pero sólo son parte del proceso de formación del paisaje. La sucesión de períodos críticos (disminución de territorio cultivado) y períodos de crecimiento (aumento del hábitat) que los geógrafos reconocen en la historia del paisaje (Chouquer, 1996: 218) impone una visión cíclica y provocadoramente esquemática de la dinámica histórica. No obstante sirven para destacar que en esa relación de hitos no están representadas amplias etapas en las que la explotación de la ZAMB ha sido un hecho, precisamente las que podrían corresponder con períodos de aumento de la superficie cultivada y disminución consiguiente de las evidencias constructivas.

Ese proceso no está definido y las amplias fases de explotación del suelo que podrían aislarse utilizando los distintos trazados de las redes de irrigación, o la adscripción cronocultural de las evidencias constructivas, no están suficientemente enlazadas, ni fundamentadas. Su descripción pormenorizada deberá esperar a reconstrucciones paleomorfológicas que ayuden a explicar las diversas secuencias constructivas y pedosedimentarias que se van reconociendo. A pesar de ello sí se puede adelantar que ese proceso no está determinado ni por los condicionamientos ambientales locales (geológicos, geomorfológicos o ecológicos) ni por la herencia activa de las ocupaciones previas, lo que quiere decir que no puede ser explicado sólo desde la información que aporta la zona arqueológica. Los modelos de dispersión del hábitat o la organización de los regadíos hispanomusulmanes no está condicionada por la herencia de los sistemas romanos de irrigación, ni éstos, por supuesto, por los prehistóricos. Por ejemplo el hecho de que determinados emplazamientos nuevos revelen un conocimiento práctico de las potencialidades hídricas de un lugar concreto, no significa que reconozcan que esas ventajas provengan de la existencia soterrada de un sistema de canales abandonado que ordena la circulación de las aguas subterráneas.

Con esto queremos insistir en que la escala de investigación (local) no permite extrapolar hipótesis fundamentadas para todos los momentos del proceso de ocupación y explotación del sitio, lo que no va a impedir que con apoyos en investigaciones previas de menor escala se intente enmarcar su desarrollo particular en las secuencias completas de ámbito regional. Es indispensable disponer de su-

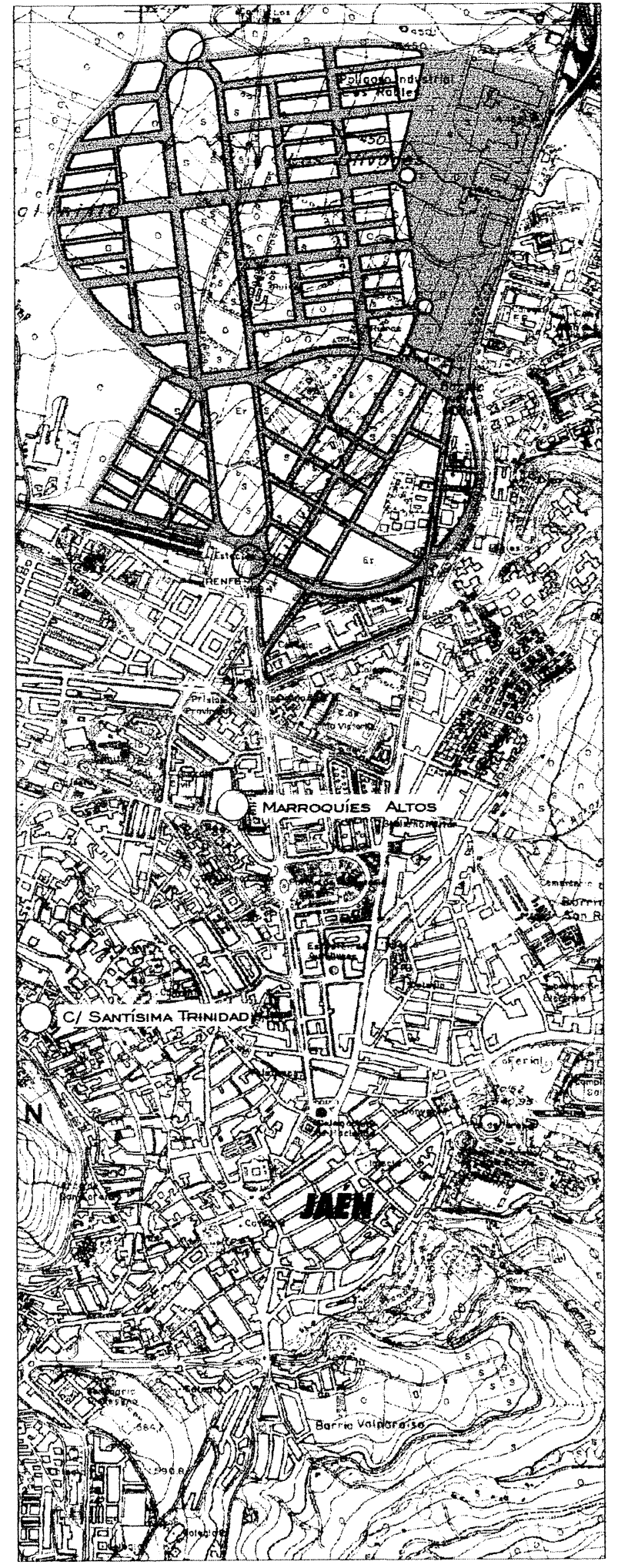

Fig. 2. Delimitación de la Zona Arqueológica de Marroquíes Bajos. Escala base 1:10.000. 
cesivos modelos de ocupación del territorio en los que encajen las particularidades de cada una de las comunidades que han contribuido a la formación de la ZAMB. La dinámica social y económica de las formaciones sociales prehistóricas, interpretada para la provincia de Jaén por Ruiz (1982), Ruiz et alii (1986), Nocete (1988 y 1994), Contreras et alii (1993 y 1997) y Lizcano et alii (1991-1992) son un punto de referencia obligado para contextualizar las interpretaciones sobre el asentamiento de Marroquíes Bajos y su articulación en una jerarquía territorial. Como por otra parte son indispensables los distintos modelos de desarrollo social descritos para el sureste por Lull (1983), Ramos (1981), Gilman y Thornes (1985), Chapman (1991) oArteaga (1992) como base de interpretación del marco de interrelaciones entre formaciones sociales. Estas mismas necesidades son obvias para el resto de las etapas definidas, las investigaciones sobre la cultura ibérica realizadas desde 1980 por Ruiz y Molinos y su equipo (1986, 1989, 1993); las romanas de Castro (1989) y Gutiérrez (1998); las medievales de Salvatierra y Castillo y su equipo $(1989,1997)$ o Quesada (1989) son el contrapunto macroterritorial de las evidencias locales extraidas durante las intervenciones.

Las características generales de cada una de esas ocupaciones las hemos abordado en un trabajo anterior (Hornos et alii, 1998) y en concreto las etapas históricas han sido objeto de atención preferente en el número 4 (1997) de Arqueología y territorio medieval, revista del Área de Historia Medieval de la Universidad de Jaén. No obstante consideramos necesario recoger aquí (Tab. 2) una primera aproximación a las etapas de ocupación de la ZAMB, indispensable para abordar la sistematización de la abundantísima información que se está generando.

\section{EL ASENTAMIENTO PREHISTÓRICO: TIEMPO Y FORMAS}

A los asentamientos prehistóricos corresponderían las 5 primeras fases. En este texto trataremos superficialmente las fases 1 y 5 , centrándonos en el periodo de ocupación masiva de la ZAMB que abarca desde c. 2500 cal.ANE hasta c. 2000 cal. ANE (2) (ZAMB 2-3-4), momento en el que Marroquíes llega a tener una extensión amurallada

(2) Todas las dataciones radiocarbónicas de este asentamiento utilizadas en el texto han sido calibradas con el Radiocarbon Calibration Program Rev 3.0.3. (Stuiver y Reimer, 1993).

\begin{tabular}{|c|c|}
\hline ZAMB 1 & Cobre antiguo, Cobre Pleno \\
\hline ZAMB 2 & COBRE FINAL-PRECAMPANIFORME \\
\hline ZAMB 3 & COBRE FINAL-CAMPANIFORME \\
\hline ZAMB 4 & Cobre Final-Bronce ANTIGUO \\
\hline ZAMB 5 & BRONCE PLENo \\
\hline ZAMB 6 & CULTIVOS PRE Y PROTOHISTÓRICOS \\
\hline ZAMB 7 & IBÉRICO TARDÍO-ROMANO REPUBLICANO \\
\hline ZAMB 8 & Augusteo-JuLIo/CLAudio \\
\hline ZAMB 9 & FLAVIO-ANTONINO \\
\hline ZAMB IO & MEDIO Y BANO IMPERIAL \\
\hline ZAMB I I & HISPANOGODO \\
\hline ZAMB I 2 & ANDALUSÍ EMIRAL \\
\hline ZAMB I 3 & ANDALUSí CALIFAL \\
\hline ZAMB I 4 & ANDALUSí ALMOHADE \\
\hline ZAMB I 5 & Castellana \\
\hline ZAMB 16 & ESPAÑOLA MODERNA \\
\hline ZAMB I 7 & ESPAÑOLA CONTEMPORÁNEA AGRARIA \\
\hline ZAMB I 8 & ESPAÑOLA CONTEMPORÁNEA URBANA \\
\hline
\end{tabular}

Tab. 2. Fases de la ZonaArqueológica de Marroquíes Bajos.

de $340.000 \mathrm{~m}^{2}$ y un sistema de captación y distribución de aguas que abarcaba mas de un millón de $\mathrm{m}^{2}$ (Fig. 3 y 5 ).

La periodización la hemos fundamentado en el reconocimiento de segmentos del proceso histórico en el que las evidencias de continuidad en el espacio se cruzan con las de cambio en las manifestaciones culturales. Hemos reconocido distintos momentos del proceso (3) intentando mantener la coherencia entre los presupuestos teóricos, la escala de la investigación y la proyección de las inferen-

(3) El concepto de 'momento del proceso' expresa la posición en el "tiempo cultural" de un determinado periodo bien caracterizado. El concepto de 'tiempo cultural' (Chang, 1976: 37; Ruiz y Molinos, 1993: 96; Assmann, 1995: 6) es el complemento necesario para elaborar las generalizaciones a partir de los datos del tiempo histórico de cada formación social. 


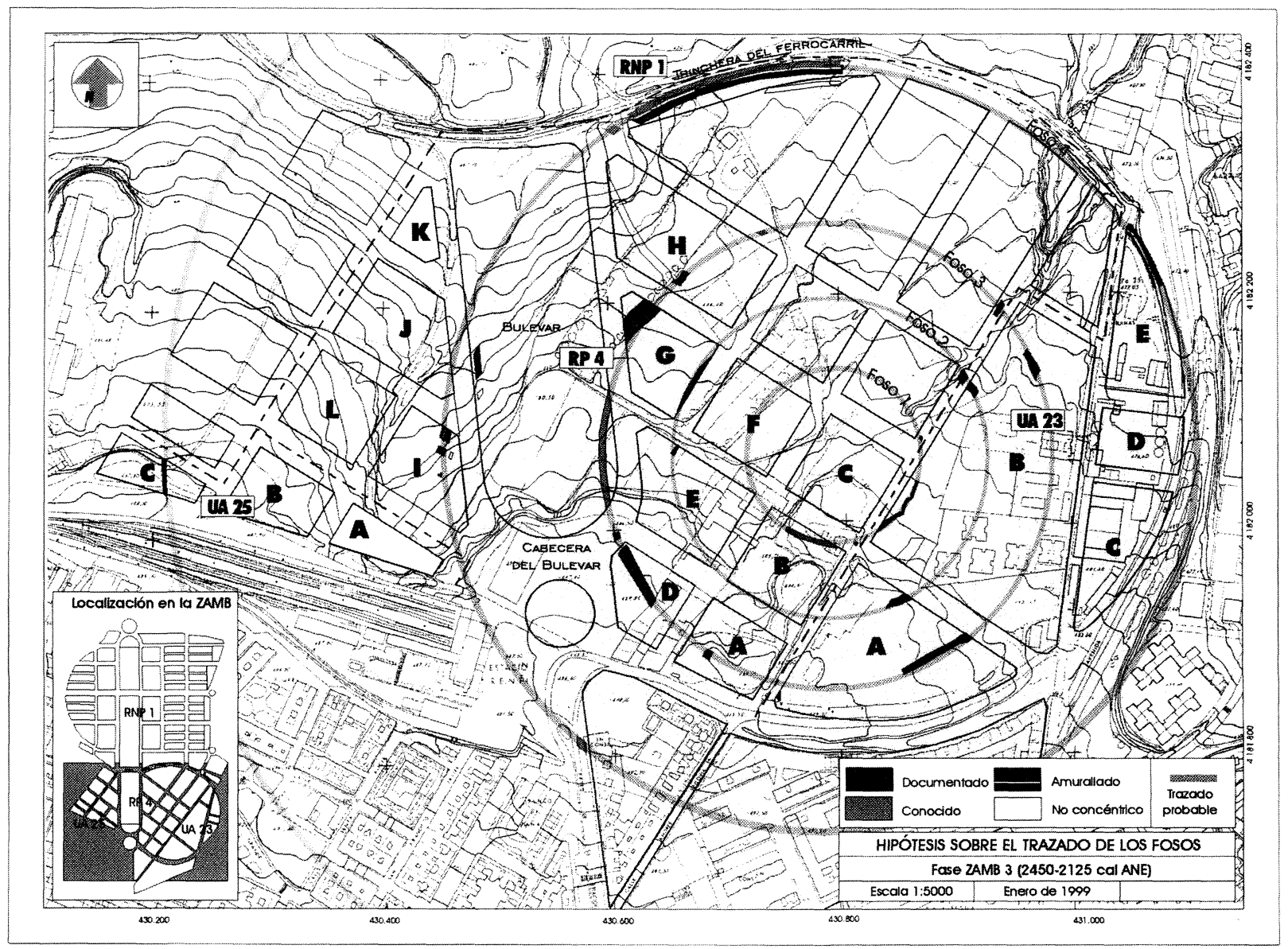

Fig. 3.

cias. Pretendemos postular teorías que contengan conceptos y categorías inobservables pero básicos para explicar e interpretar la estructura de las sociedades y los procesos históricos (proceso de trabajo, modo de producción, relaciones de producción, formación social, etc.). Consideramos indispensable establecer vínculos históricos entre los fenómenos arqueológicos observables. A tal efecto presentamos un primer bloque de hipótesis basadas en datos que proceden de investigaciones en curso, cruzados con los resultados de análisis palinológicos y radiocarbónicos puntuales.

Este cuerpo de hipótesis se articula en tres escalas de aproximación: doméstica leida en la asociación de lugares de actividad; local, interpretada a través de los rasgos del paisaje construido; y territorial apoyada, por el momento, en las interpretaciones de marco regional realizadas por otros autores. Trataremos con algún detalle las escalas micro y meso, incluyendo descripciones y análisis. Las interpretaciones de ámbito macroespacial se encuentran en fase de tentativa y figuran en la medida en que son necesarias para llegar a comprender determinadas dinámicas del proceso que hemos leído en las escalas mayores.

\subsection{Una aproximación a los espacios domésticos}

Si con Engels aceptamos como factores determinantes de la evolución histórica la producción de los medios de existencia (alimentos, vestidos, vivienda, instrumentos) y la reproducción de la especie humana, tendremos que admitir que la arqueología es una disciplina particularmente capacitada para el estudio de la evolución de los primeros, y muy limitada en los desarrollos metodológicos que arrojarían luz sobre los mecanismos y funciones de la segunda. 
A pesar de ello, como quiera que la investigación que presentamos aquí está circunscrita al interior de un asentamiento y sabiendo que a esa escala ignorar las relaciones que aseguran la reproducción doméstica es desconocer las formas de reproducción social de la comunidad, destacaremos aquí las hipótesis que nos guían en su conocimiento, a través de lo que consideramos la menor unidad espacial socialmente significativa: el complejo doméstico. Partimos del supuesto de que la disposición interior del asentamiento obedece a un orden social condicionado por su historia y su función, ordenamiento conseguido en este caso mediante la agregación de unidades sociales menores: las unidades domésticas.

La unidad doméstica es un mundo con reglas propias pero no independiente que se instituye como la célula social básica. En su seno las relaciones (de producción, de poder, de dependencia) se establecen sobre la base de la diferencia, legitimando la desigualdad. Hay roles fijados por el género, la edad y la procedencia, que reparten las funciones productivas-reproductivas de cada componente y las formas de transmisión y herencia. El reparto de funciones y la consiguiente asignación de espacios no es un acto automático, la multifuncionalidad, o mejor interfuncionalidad de los mismos introduce un sano nivel de incertidumbre que impide las asociaciones presentistas, obligando al cruce de inferencias de procedencia múltiple. Por ello, pese a saber que en la unidad doméstica la relación hombre-mujer fija de forma determinante el marco de acciones, influencias y comportamientos, en el actual estado de conocimientos sólo podemos acceder a un nivel superficial de las relaciones de dominio-dependencia en el interior de la familia y, hasta que se puedan demarcar los ámbitos de hombres y mujeres en el seno de la unidad doméstica, asumimos ésta como unidad social mínima.

El complejo doméstico es la expresión material de la unidad doméstica, un conjunto unitario de construcciones que, en lo esencial, se repiten en el interior del asentamiento. La evolución de las distintas articulaciones espaciales en que se encarnan las unidades domésticas no es conocida con precisión, pero comenzamos a disponer de información que permite formular algunas hipótesis sobre estructuras e implicaciones históricas. Hay que señalar, no obstante, que estos apuntes sobre los caracteres morfológicos y funcionales de las unidades domésticas de cada fase son meros esbozos que no pueden considerarse definitivos hasta tanto se finalizan las excavaciones y los análisis en curso, ni

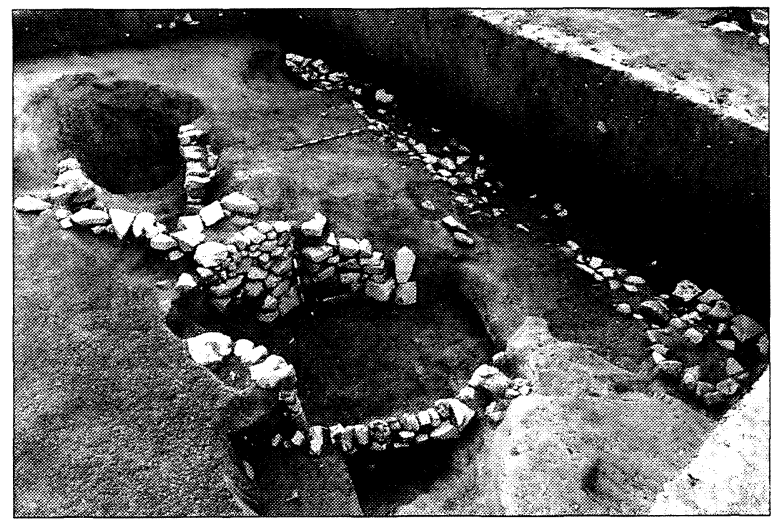

Lám. II. Estructura subterránea localizada en la trinchera del ferrocarril. Fotografía J.L. Serrano (Archivo de la Delegación Provincial de Jaén).

tampoco se deben entender como extrapolables directamente a otros asentamientos, ni siquiera a todas las áreas del propio asentamiento. Las diversas composiciones de cada unidad doméstica y su evolución específica deciden el tamaño, la forma y la función del complejo y de cada ámbito del mismo. Su valor por ello es indicativo no normativo.

En la ZAMB es el cambio en las técnicas constructivas y la posición en la secuencia sedimentaria lo que nos ha guiado en la detección y definición de los complejos domésticos. Están en marcha estudios de materiales para apoyar estos datos con adscripciones funcionales precisas de cada uno de los elementos del complejo. Se conoce que a las estructuras subterráneas y semisubterráneas de la primera ocupación (Lám. II), se les superponen las de hoyos de poste y surco de cimentación perimetral (Lám. III), siendo estas desbancadas tras unas pocas generaciones por conjuntos que, aunque mantie-

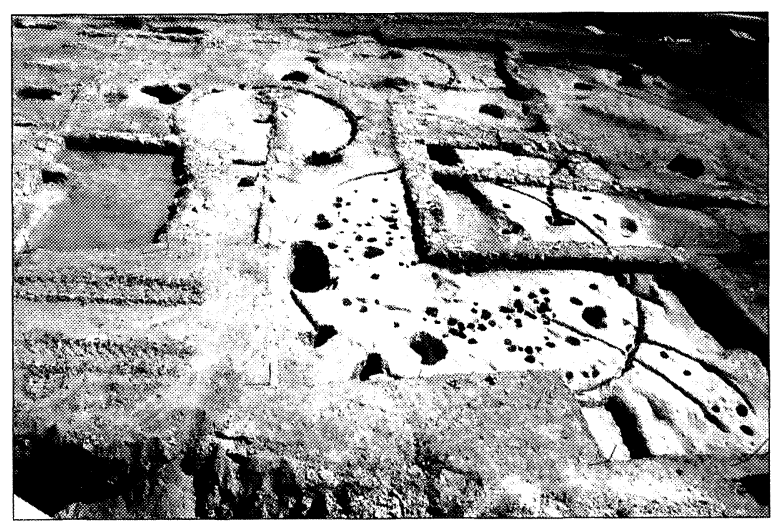

Lám. III. Construcción de surco perimetral (ZAMB 3) en la parcela E1-E3 de la UA 23. Fotografía ARTRA (Archivo de la Delegación Provincial de Jaén). 


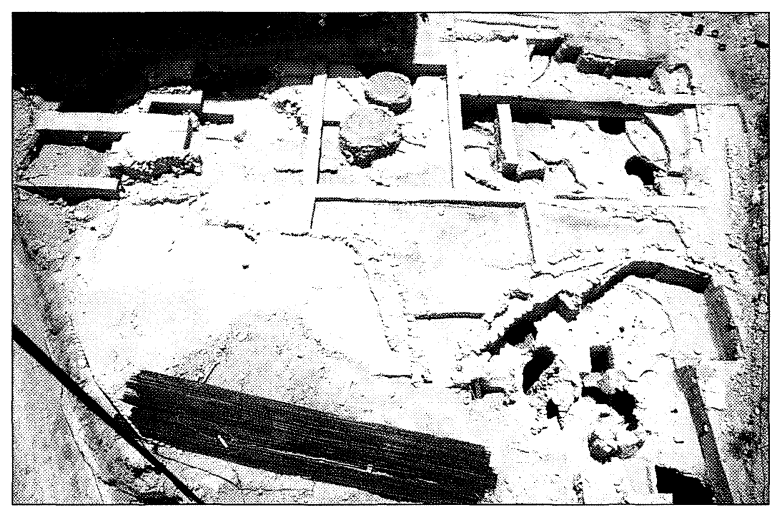

Lám. IV. Límites de complejos domésticos y "calle" de ZAMB 4 en la parcela E 2-4 de la UA 23. Fotografía N. Zafra (Archivo de la Delegación Provincial de Jaén).

nen en parte los materiales de construcción (madera y adobes), y la morfología de algunas unidades de cobijo (circularidad, techumbre cónica) quedan ahora delimitados por recintos de piedra y adobe (Lám. IV).

En la fase ZAMB 2 (como en ZAMB 1), residencia, silos, vertederos, tumbas y “talleres" están excavados en el sustrato geológico, creando en ocasiones auténticas colmenas con diversos cubículos enlazados entre sí y accesos múltiples -parcela A 4,5,6 de la UA 23, parcela B del RP 4, cabecera del bulevar, o parcela D del RP 4. En ZAMB 3 se documentan importantes extensiones de edificaciones al aire libre, con estructura de madera. Las plantas de construcciones circulares definidas por hoyos de poste y surcos de cimentación perimetrales se extienden por todo el asentamiento: parcelas E 2-4, E 2-5, E 2-6, E 1-3, parcela D y parcelaA de la UA 23; manzana G del RP 4 y cabecera del bulevar. Son frecuentes las puertas sobresalientes (a menudo verdaderas portadas), hogares o complejos sistemas de sustentación y en la parcela E 1-3 de la UA 23 se ha excavado lo que parece una estructura de paredes rectilíneas construida con grandes troncos, aunque su estado de conservación no ha permitido precisar si su planta era rectangular, siendo en esta fase la única edificación documentada con tal morfología (Lám. III).

La construcción de complejos domésticos cercados que correspondería a ZAMB 4 no desprecia los conocimientos constructivos anteriores y, manteniendo las construcciones de surco perimetral (ahora muy difíciles de detectar por encontrarse excavadas sobre tierra y no sobre margas), introduce la cimentación de piedra, llegando a levantar cabañas de $8 \mathrm{~m}$. de diámetro con zócalos de $0,5 \mathrm{~m}$. de gro- sor (manzana G del RP 4). Naturalmente en todas las fases (y no sólo en las prehistóricas) se han continuado excavando estructuras subterráneas (pozos, silos, canales, tumbas...), y no es sensato pensar que las sustituciones en las tradiciones constructivas fueran repentinas ni completas. Nos inclinamos por procesos de cambio paulatinos en los que diversas maneras de construir "coexisten".

La asociación de estas evidencias constructivas de ámbito general en conjuntos asimilables acomplejos domésticos exige una labor de interpretación que se reveló mas asequible en la ZAMB 4, uno de cuyos complejos domésticos ha sido localizado en tres intervenciones arqueológicas en el lado noreste del asentamiento: E 2-4, E 2-5 y E 2-6 de la Unidad deActuación 23 (Fig. 4). Nos encontramos ante un conjunto estructural diverso delimitado por un muro de escasa altura, en el que un acceso permite la salida hacia una "calle" que conduce a una de las puertas de la muralla. En su interior, mucho mas limpio y cuidado que el entorno, se detectan suelos construidos con capas de margas o piedras sobre los que se edifican las cabañas que, aquí, se levantan con postes de sección reducida (o tablas) y adobes, presentando compartimentaciones, bancos de trabajo, hogares... Junto a éstas se localizan un pozo, varias estructuras subterráneas (¿almacén?, vertedero), cabañas (con hogar y sin hogar), diversos lugares de actividad al aire libre (molienda, cocina...) y otras construcciones sin función conocida. La cerca (muro que delimita el complejo) es una construcción de adobe con cimientos de piedra que acota este espacio durante el tiempo suficiente para requerir reconstrucciones y labores de mantenimiento.

Frente a éste se encuentran otros complejos rodeados de cercas de similar factura excavados parcialmente. Hay ejemplos de complejos de esta fase en la trinchera del ferrocarril (límite norte del RP4) donde se reconocen sus límites oriental y occidental pero en los que la estrechez del área de excavación impide conocer la superficie total o la composición estructural específica. Restos de algunos otros se han localizado en la cabecera del bulevar, en la manzana E del RP4 y en la manzana F del RP 4. Merecen especial atención las agrupaciones de estructuras excavadas en la manzana G del RP 4, donde se han documentado las cabañas de mayor tamaño y mejor factura, cuyo estudio podrá en el futuro informarnos sobre la desigualdad entre complejos y sus implicaciones sociales. Asimismo en la manzana E del RP 4 se han excavado estructuras rectangulares adscribibles a esta fase. 




Fig. 4.

T. P., 56, n. ${ }^{\circ} 1,1999$ 
Este complejo doméstico es fruto de una evolución cuyos rasgos generales comenzamos a atisbar. En la fase inmediatamente anterior, ZAMB 3 (construcciones mayoritariamente cilindrocónicas de madera y barro reflejadas en hoyos de poste y surcos de cimentación perimetrales con portada), en los lugares donde el nivel de conservación lo ha permitido se ha observado, por rasgos indirectos, el agrupamiento de varias estructuras: orientación de los accesos a un espacio común (E 1-3), subdivisión del espacio mediante superposición de 2 estructuras sobre una preexistente (cabecera del bulevar), especialización de las estructuras: grandes cabañas con hogar central y 4 postes interiores de sustentación (A 4-6, E 1-3, ), cabañas con poste de sustentación central sin hogar (A 4-6, E 1-3), estructuras rectilíneas (E 1-3), horno (galería visitable del RP 4 ), etc. Con ellas se localizan algunos enterramientos como los de las parcelas E 2-6 de la UA 23 o D $1,4,5$ de la UA 23 que interpretamos como "panteones familiares" subterráneos que tienen en común no agruparse en necrópolis, encontrarse en el interior del asentamiento entre estructuras domésticas y no presentar ajuar ni ofrendas perdurables. En las estructuras subterráneas de ZAMB 2 también se han reconocido unidades domésticas (parcela 15J del RP 4) constituidas por grandes estructuras de cobijo y descanso asociadas a otras de menor tamaño destinadas a diversos usos (almacenaje, cocina, etc.), aunque sin precisión en cuanto a sus límites y composición.

\subsubsection{La institucionalización de la casa}

Estas observaciones pueden indicar que cada unidad doméstica tenía asignada ya en las fases iniciales su superficie de residencia y reproducción, cuyos límites no hemos sabido leer, que está evidenciando una división de la superficie del asentamiento. Pero no conocemos áreas cercadas que subrayen un uso exclusivo. Por lo que mantenemos, en principio, que persiste una apropiación colectiva del suelo, apropiación efectiva y no simple patrimonialización al menos desde ZAMB 3.

En todo caso lo que planteamos como hipótesis es la existencia de una particularización de los medios de producción: determinadas familias tienen derechos concretos sobre tierras señaladas y delimitadas. Esto podemos defenderlo para la fase ZAMB 4 (c. 2125-1975 cal.ANE) pero no para las anteriores. Por el momento no podemos precisar cuándo se reparte la tierra, sólo que el proceso se produce entre ZAMB 3 y ZAMB 4 (c. 2450-1975 cal. ANE). Apoyan esta hipótesis las escasas tumbas localizadas en el recinto de la macro-aldea que son adscribibles a ZAMB 3. Asumimos que su presencia informa de los derechos sobre el lugar que se habita y de la necesidad de apoyarse en los antepasados para legitimar esos derechos, en un momento en que la familia comienza a asumir funciones que, hasta entonces, correspondían a la comunidad.

¿Cómo podemos llegar a interpretar esto en Marroquíes Bajos? Hemos visto cómo en la fase ZAMB 4 la compleja articulación de espacios y la asociación de formas y funciones nos hablan de un ámbito doméstico multifuncional, que tiende a satisfacer necesidades básicas de la vida cotidiana: procesos de producción alimentaria, cobijo, descanso, consumo, higiene... y, junto a ellas, otras funciones como el abastecimiento de agua que expresan cierto nivel de autonomía subsistencial. Todo ello cercado por un muro que marca los límites en el poblado de lo que denominaremos la casa (4). Según Leduc (1992: 256) un conjunto compuesto por “1) la casa, 2) su contenido, las cosas poseidas, 3 ) la parcela de tierra y 4) el ganado", incluyendo como hace Mossé (1983: 17-18 citado en Leduc, 1991: 256) al grupo humano que la habita y explota.

Percibimos este complejo arquitectónico cercado como una expresión afirmante de la apropiación de la parcela de residencia. Una afirmación que es un signo de pertenencia a la comunidad (pues su propia existencia implica el sometimiento a las normas establecidas) y al mismo tiempo una demostración del poder de la unidad doméstica, de su capacidad de actuación autónoma dentro de aquélla. La base en que se sustenta esta autonomía es la tierra a la que suponemos parcelada al igual que el poblado, latierra ahora explotada por y para la familia.

El materialismo dialéctico y su cosmovisión integradora nos induce a defender que un cambio en la forma de la unidad doméstica, por ejemplo el cercado del complejo doméstico, supone necesariamente un cambio en la esencia de la misma, en las relaciones que la sustentan. Interpretamos el cercado de la parcela como signo de la descentralización de la economía del asentamiento, con la apropiación de la tierra por parte de la unidad doméstica y su transmi-

(4) Este concepto se asocia generalmente a sociedades con herencia única, en las que las parentelas se organizan en torno a la casa, frente a las de herencia igualitaria que se centran en torno a un individuo (Bestard Camps, 1991: 121 citado en Martínez López, 1996: 193), aquí se utiliza sin considerar la forma de transmisión. 
sión dentro del núcleofamiliar. La comunidad que accede a esta práctica se ve en la inmediata obligación de definir los modos de descendencia (matrimonio y herencia) que deben asegurar la transmisión para mantener el sistema.Ahí está la clave del cambio en el ámbito doméstico: la posibilidad de heredar la tierra o derechos sobre la misma hace que la mujer se torne bruscamente peligrosa. Si hasta ese momento podía circular entre las unidades domésticas del grupo como un factor de reproducción de la cohesión, a partir de ahora puede disolver la unidad doméstica renovada. Las reglas y estrategias de enlace y los mecanismos de sucesión y herencia surgen para imponer un cinturón protector (una política defensiva) a la nueva relación que puede adoptar formas de endogamia "doméstica" o distintas estrategias de afiliación unilineal, dependiendo de la composición de cada grupo familiar (5).

La asociación familia-tierra, es decir, la institucionalización de lacasa marca el origen de los modos de vida campesinos, que basan su existencia en la explotación familiar de la tierra y su pervivencia en la capacidad de transmitir lacasa a la descendencia (sea en propiedad o en cualquier otro modo de apropiación que garantice su acceso a la misma) de manera que quedan ligados a la tierra para reproducir su medio de trabajo. Se conforma una sociedad de pequeños productores que va sustituyendo a la estructura mas amplia de la sociedad segmentaria. Las relaciones de propiedad y la existencia de las unidades nucleares de interacción social se utilizan como indicadores de este cambio, ambos elementos han sido empleados por Shanin (1983: 282) para caracterizar al campesinado.

Esa dinámica y el proceso por el que la hemos intentado explicar desde la escala doméstica tienen una lectura en el asentamiento que se aborda a continuación.

\subsection{Evolución de la estructura del asentamiento}

Marroquíes Bajos es un espacio que concentra población y poder cuya organización social se situa entre la comunidad parental, definida por las relaciones entre personas, y la ciudad basada en las relaciones de propiedad y pertenencia territorial. Nos

(5) Wolf (1975: cap. 3) indica que en situaciones de concentración de recursos y trabajo el tipo de familia campesina predominante es la extendida, categoría que abarca los tipos extensa (familia nuclear + parientes o elementos ajenos miembros de la unidad económica) y múltiple (dos matrimonios o mas) de la clasificación de Laslett y el "Cambridge Group" (Laslett y Wall, 1972). hemos propuesto explicar el movimiento por el cual esa comunidad, con mecanismos de producción y reproducción encaminados a su pervivencia, sufre un fenómeno de transferencia que a la postre la disuelve. Hemos determinado las siguientes fases del proceso: colonización (fecha indeterminada, ZAMB 1); concentración poblacional y origen de la macroaldea (??-2450 cal.ANE, ZAMB 2); intensificación agraria (2450-2125 cal.ANE, ZAMB 3), campesinización (6) (2125-1975 cal.ANE, ZAMB 4) y dispersión (a partir de 1975 cal.ANE, ZAMB 5).

A ZAMB 1 adscribimos dos pequeños núcleos de población asentados en la margen oriental del Arroyo de la Magdalena que representan, por el momento, la primera ocupación del sitio. No se dispone de fechas absolutas, sin embargo su conjunto material y su tipo de inhumaciones parecen no dejar lugar a dudas sobre su posición en la secuencia. Se localizan en el borde norte del RP4 y en el límite occidental de la cabecera del bulevar. En ambos la evidencia primera son inhumaciones colectivas en "fondo de cabaña" excavado en la base geológica, de entre $0,25 \mathrm{~m}$. y $0,40 \mathrm{~m}$. de profundidad, sin ajuar ni ofrendas perceptibles. La morfología de estos enterramientos es similar a la del documentado en el Polideportivo de Martos (Jaén) (Lizcano et alii, 1991-1992: 89) aunque este último es anterior. Concretamente junto al enterramiento del borde norte del RP4 se han localizado una serie de estructuras subterráneas y zanjas de escasa profundidad y trazado rectilíneo con materiales cerámicos que pueden retrotraerse hasta un momento inicial de la Edad del Cobre. Podemos hablar pues, de una ocupación dispersa en las márgenes del Arroyo de la Magdalena en un momento temprano de la Edad del Cobre, que sería la primera colonización del sitio.

ZAMB 2 es el resultado de un proceso de concentración poblacional que provoca a medio plazo la construcción de la macro-aldea. Este hecho supone una importante inflexión que impone para las fases ZAMB 2-3-4 una cierta unidad, basada en la continuidad, en la que se reconocen dos cambios en el proceso productivo. El primero, que marca la distinción entre las fases ZAMB 2 y ZAMB 3, atañe a las fuerzas productivas, es el paso de la tierra-medio de

(6) Este concepto ha sido acuñado para los procesos de colonización agrícola impuestos por las revoluciones liberales en la Andalucía contemporánea (González y Sevilla, 1993), entendiendo que la penetración del capitalismo en el campo andaluz provocó una campesinización previa a la proletarización. Aquí lo utilizamos para señalar el origen del modo de vida campesino en la zona y no su reimplantación o potenciación.

T. P., 56, n. ${ }^{\circ} 1,1999$ 
trabajo a la tierra-medio de trabajo construido, lo que significa una intensificación en las prácticas productivas (fruto del cultivo permanente propiciado por el regadío) y una mayor dependencia del lugar de explotación. Los estudios en marcha podrán confirmar si, junto a esto, se aprecian otros "síntomas" de la denominada segunda revolución agraria o "revolución de los productos secundarios" (Sherrat, 1981; Harrison y Moreno, 1985): introducción del arado, alternancia de cultivos, barbecho, aprovechamiento de los productos lácteos y textiles derivados del ganado, etc. En el segundo (ZAMB 3 a ZAMB 4), que modifica las relaciones de producción, creemos reconocer un proceso de campesinización, con el reparto de la tierra y la subsiguiente implantación de sistemas familiares de transmisión de la misma, que apuntan hacia la existencia (en la fase ZAMB 4) de estrategias productivas y estructuras sociales campesinas que sustituyen a las dominantes en las sociedades paleoagrarias.

ZAMB 2 es una aldea subterránea que ocupa con el tiempo una gran extensión, no sabemos si por los traslados sucesivos de unidades de residencia de amortización rápida o por una expansión poblacional. En ella se documentan grandes estructuras de cobijo y reproducción subterráneas que, aunque están presentes en buena parte de la zona arqueológi$\mathrm{ca}$, se concentran en el área oriental de mayor altitud y menor potencia sedimentaria. Se desconocen los límites de su recinto y las características de éste, aunque jugamos con la idea de un asentamiento rodeado por uno o varios fosos y sin muralla localizado en las zonas altas de laZAMB (sur de la UA 23 y sureste del RP 4) que con el tiempo quedaría englobado por la red de fosos y la fortificación de ZAMB 3.

El asentamiento durante ZAMB 3 (2450-2125 calANE) es una superficie aproximadamente circular organizada mediante fosos concéntricos excavados en las margas con secciones en "U" o en "V", profundidades entre 1,5 y $5 \mathrm{~m}$. y anchuras de entre 4 y $22 \mathrm{~m}$. Contienen refuerzos internos de adobe $\mathrm{o}$ piedra y evidencias en su fondo de circulación de agua. Conocemos 5 fosos (7), aunque no se descarta la existencia de otros (Fig. 3).

El primer foso con un radio de entre 50 y $70 \mathrm{~m}$. rodea el centro del asentamiento $\mathrm{y}$, a tenor de la

(7) Hemos especulado con la posibilidad de un sexto anillo exterior a los conocidos (Hornos et alii, 1998) pero no se ha visto confirmado por los nuevos datos. También hay que señalar que, por grado de conservación o insuficiencia de datos, algunos tramos de fosos conocidos no han podido ser integrados en el esquema descrito (borde norte del RP 4; A 4,5,6 de la UA 23; galería visitable del bulevar). estructura del espacio, tendría un papel destacado en la organización del poblado. Se ha localizado sólo en su lado oriental, parcela B 2-5 de la UA 23 y C/ Marroquíes Bajos, lo que dificulta la proyección de su trazado. Las intervenciones han revelado una anchura variable (4-5 m.), una sección en "U" ataludada y una profundidad desigual. Su característica mas destacable es la presencia de dos bastiones y una empalizada que lo bordea en su línea interna. El conocimiento de la organización del poblamiento en este círculo central debe postergarse hasta la realización de intervenciones en lo que se pretende sea una de las áreas musealizadas del sitio (8). El segundo foso con un radio de entre 140 y $150 \mathrm{~m}$. se ha detectado en la UA 23 parcelas B93, A4-A6 y C/ Marroquíes Bajos y en el RP 4 (Manzana $E$ y Manzana $G$ ). Su anchura es muy variable (4-16 m.) a lo largo de los más de $800 \mathrm{~m}$. de perímetro con una sección en "V" y profundidades diversas. En el sector oriental engloba una ocupación muy densa. El tercer foso presenta un radio de entre 200 y $210 \mathrm{~m}$. Se ha localizado en la UA 23 parcelaA1, A6 y B10 así como en el RP 4 parcela A3, manzana D (Lám.V), manzana G, bulevar , manzana $\mathrm{H}$ y viales. Este anillo de sección en "V" en la mayor parte del trazado, muestra anchuras de entre 5 y 22 m. y una evolución muy marcada de su morfología, apreciable especialmente en la manzana $\mathrm{G}$.

El cuarto foso, con un radio de 330-360 m., se ha localizado en el Paseo de la Estación, en la manzana I del RP 4, bulevar, trinchera del ferrocarril y E24 de la UA 23. Presenta una morfología especial en el conjunto del sistema, ya que en el sector occidental su línea exterior está construida con un gran muro de adobe de $2 \mathrm{~m}$. de ancho (parcela I del RP 4). Esto parece impuesto por la necesidad de mantener la circularidad del trazado y simultáneamente una cota determinada en ese punto, lo que debido a la pendiente natural del terreno impide conseguirla mediante su excavación. Este cuarto foso se instituye como la línea exterior del poblado como demuestra el hecho de que se encuentre reforzada por una muralla. La construcción de esta línea fortificada, que conforma el lado interior del cuarto anillo, exige el desvío del Arroyo de la Magdalena, que bordea al asentamiento por el oeste. Se realizaron obras de protección frente a avenidas, formando plataformas (parcelas I y J del RP4) y muros (bulevar).

La muralla, localizada en la manzana I del RP 4,

(8) Se ha conseguido recalificar los terrenos modificando el Plan Parcial para convertirlos en espacios dotacionales, no lucrativos. 


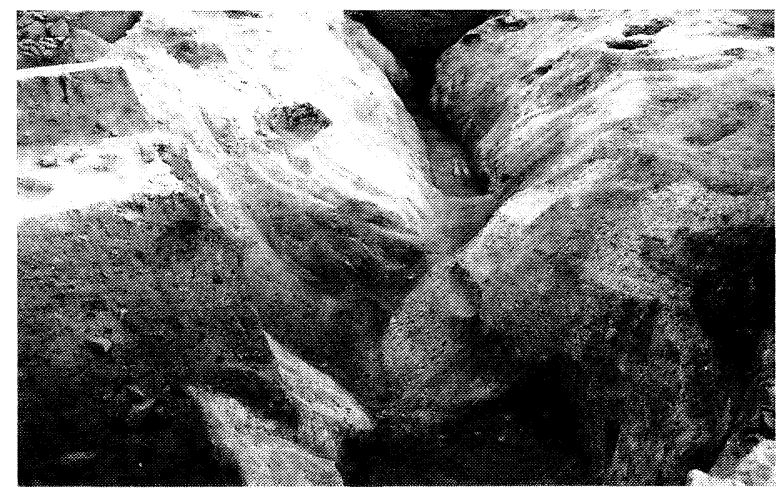

Lámina V. Vista de un tramo del foso 3 excavado en la parcela D del RP 4. Fotografía A. Burgos (Archivo de la Delegación Provincial de Jaén).

en el bulevar, en la trinchera del ferrocarril y en la parcelaE2-4 de la UA 23, delimita una superficie de 34 ha. Se conforma como un cinturón de adobe con un perímetro de $2 \mathrm{~km}$. y un grosor variable cuya mediana en los tramos excavados es de $2 \mathrm{~m}$. Su altura estimada es de, al menos, 3 m. (9). En la construcción se utilizaron adobes cuadrangulares de aproximadamente $20 \times 20 \times 10 \mathrm{~cm}$. trabados con argamasa dispuestos en tongadas. Entre cada tongada se interponía una plataforma de piedra para darle mayor consistencia y conseguir un nuevo plano estable. No se ha mencionado la existencia de revoco, pero parece indispensable para asegurarle cierta perdurabilidad. Esta gran estructura (al menos $12.000 \mathrm{~m}^{3}$ de adobe y piedra) se completaba con bastiones semicirculares como los detectados junto a una de las puertas en la parcela E 2-4 de la UA 23 o en el bulevar del RP4 construidos con piedra.

Un centenar de metros al norte de la manzana $\mathbf{J}$ del RP4, la complejidad del sistema de fortificación-canalización alcanza su máxima expresión. Dos grandes muros paralelos de adobe, el externo reforzado con paramento y bastión de piedra, contienen en su interior el foso (Lám. VI). La particularidad con respecto al punto anterior es que las dos paredes del mismo están construidas. La exterior con un bastión se encuentra edificada sobre una base ganada alArroyo de la Magdalena mediante la construcción de un gran muro de piedra al que, en principio, se interpreta como un gavión pero sin descartar otras opciones. El conjunto (gavión, bastión, muro exterior del foso, foso y muralla) alcanza una

(9) Estimación efectuada por Miguel Angel de Dios, director de la excavación de la parcela J-RP4, a partir de la medición de bloques de adobes desplazados en el interior del foso que circunda a la muralla. anchura aproximada de $30 \mathrm{~m}$., una estructura hidráulica-defensiva con una evolución compleja aun por detallar. En el sector oriental se han excavado dos puertas construidas con paramentos de mampostería, estructura de madera y planta irregular (Lám. VII).

A $250 \mathrm{~m}$. al exterior de la muralla nos topamos con el foso mayor, el quinto, localizado en el Sector Residencial No-Programado 1 y en la Unidad de Actuación 25 tiene un radio de $600 \mathrm{~m}$. Rodea unas tierras situadas extramuros (unas 79 ha. con los datos actuales) donde los restos constructivos son mucho menos densos que en los cuatro anillos interiores y a las que hemos considerado como los campos mas cercanos y mejor protegidos del asentamiento, lo que Hurtado (1991) reconoce en la Pijotilla como el territorio de explotación inmediata también circundado por un foso (10). La forma circular de su trazado puede variar en el sector oriental, donde el relieve hace muy difícil su proyección, pero esta apreciación está por confirmar.

Venimos sosteniendo como hipótesis que esta red hidráulica-defensiva es, en su origen, una construcción unitaria concebida para regular y utilizar los aportes hídricos de la cuenca inmediata. En ella observamos dos constantes, una funcional: la conducción de aguas y otra simbólica: la "obsesión" por la circunferencia o por el círculo (11) forma dominante en todas las escalas espaciales desde la cabaña hasta el asentamiento.

La primera observación viene a demostrar, por un lado, que los regadíos existen y que la debilidad de su evidencia en el Sureste habrá que achacarla a la parcialidad de los registros (Chapman, 1991: 183), sólo en el Cerro de laVirgen (Schüle, 1967) y en Los Millares (Almagro y Arribas, 1963) se han reconocido canalizaciones. En cuanto al Alto Guadalquivir, los fosos excavados en Los Pozos (Hornos et alii, 1987), se han interpretado como zanjas de delimitación y defensa desechando expresamente su uso como canales o drenajes, explicación esta última preferida por algunos autores para el Suroeste (Fernández y Oliva, 1985). Por otra la red hidrológica de la ZAMB indica que aquí es la abundancia de agua lo que precipita la construcción y utilización de sistemas de riego. Para el Sureste se ha defendido (Gilman y Thornes, 1985; Chapman, 1991; Ma-

(10) Curiosamente, en Andalucía a esos campos se los conoce como el ruedo.

(11) Distinción significativa entre una superficie homogénea sin jerarquizar: el círculo; y una línea claramente diferenciada con un centro destacado y una periferia: la circunferencia. 




Lám. VI. Conjunto de Fortificación y foso localizado en el bulevar (cuarto anillo). En primer plano muro de adobe exterior, tras éste el foso bordeando a la muralla de adobe. Fotografía M.C. Pérez (Archivo de la Delegación Provincial de Jaén). 


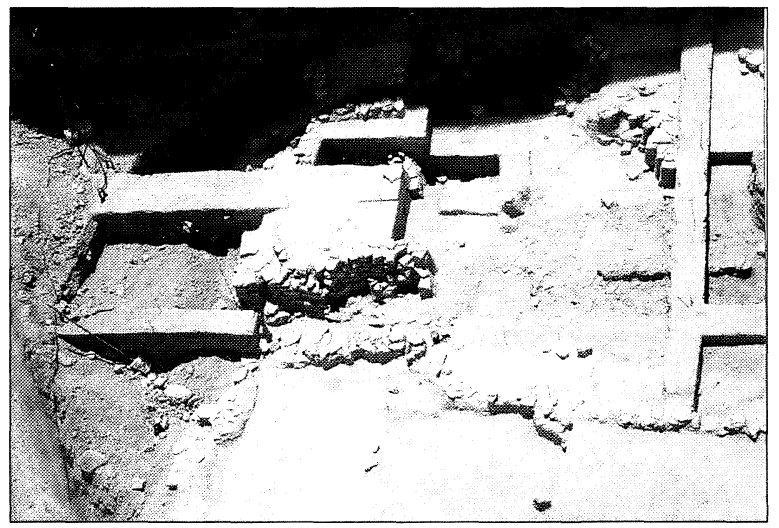

Lám. VII. Puerta en la muralla (cuarto anillo) localizada en la parcela E 2-4 de la UA 23. Por ella se accede a una "calle" definida por los límites de varios complejos domésticos. Fotografía N. Zafra (Archivo de la Delegación Provincial de Jaén).

thers, 1984; Schüle, 1986) el surgimiento de la tecnología hidráulica como adecuación de las tierras áridas a las necesidades productivas de los pobladores de la Edad del Cobre y la del Bronce, aunque el modelo de uso de la tierra propuesto en Gilman y Thornes (1985) indica que en la Edad del Bronce la relación entre intensificación y pluviosidad no es significativa, lo que supone que en ese periodo el uso de regadíos no está necesariamente asociado a medios áridos (12). Marroquíes Bajos demuestra que la capacidad técnica que hacía posible la intensificación estaba desarrollada y en una medida que supera las estimaciones mas optimistas.

En cuanto a la importancia ideológica del círculo hay que reseñar que, aunque la forma del sistema de riego y defensa trastorne nuestro sentido común, no contradice los datos que tenemos sobre las plantas de asentamientos excavados en gran parte. En efecto, mas o menos circulares y concéntricos son, sin salirnos del sur de la península, el Fortín 1 de Los Millares (Molina et alii, 1986); las Motillas de Los Palacios oAzuer (Molina et alii, 1979), las Morras como ElAcequión (Fernández-Posse et alii, 1996) en la Mancha Sur o el asentamiento extremeño de la Pijotilla (Hurtado, 1991), cuya fotografía aérea revela un trazado circular con una superficie que se

(12) Sin embargo la interacción es significativa para asentamientos Neolíticos y Calcolíticos, por lo que Gilman mantiene la hipótesis de que la agricultura de regadío ocuparía una mayor extensión en las áreas de captación de recursos de los asentamientos de estas fases, a la vez que sugiere la introducción de nuevas prácticas agrícolas intensivas en el sector húmedo durante la Edad del Bronce para explicar el fenómeno contrario (Gilman y Thornes, 1985: 176). acerca a la de Marroquíes Bajos (13). Pero el asentamiento que formalmente y a priori se parece más a ZAMB 3 y 4 es Monte da Ponte, localizado 25 $\mathrm{km}$. al suroeste de Évora, cuya representación magnetográfica muestra una extensión de cerca de $50.000 \mathrm{~m}^{2}$, organizada en 6 líneas de fortificación concéntricas de tendencia circular con dos fosos exteriores, para el que sus investigadores estiman una cronología calcolítica apoyados en los primeros sondeos realizados en 1996 (Kalb y Höck, 1997) .

Junto con la circularidad el tamaño se percibe como uno de los rasgos definitorios del sitio. Ya hemos escrito que sus dimensiones "rompen las hipótesis mas extendidas sobre los tamaños de los asentamientos y por ende sobre su volumen demográfico, que para la Edad del Cobre en el Sureste de la península se estimaban con un valor medio de 1,35 ha., variando entre 0,06 y 7,5 ha." (Chapman, 1991: 213). Las cifras de Robert Chapman no son de aplicación en elAlto Guadalquivir, donde Nocete (1989: 323) ya fijaba la existencia de asentamientos con tamaños superiores a las 12 ha. y uno, Porcuna, que superaba las 24 ha." (Hornos et alii, 1998: 84). Las estimaciones de población barajadas por Chapman, basadas en hipótesis de Renfrew (200 habitantes por ha.) supondría para Marroquíes una población mínima de 6800 habitantes casi la misma que la estimada por el propio Chapman (1991: 220) para los $6500 \mathrm{~km}^{2}$ de la "región oriental de Granada". Lo cierto es que las superficies que barajamos para cada complejo doméstico de la ZAMB 4 oscilan entre 500 y $1000 \mathrm{~m}^{2}$, lo que nos daría un número de unidades domésticas de entre 200 y 300 , muy alejado de las cifras de Chapman. Estos contrastes vienen a proponer cautela en las elaboraciones de esta índole, no sólo por la excesiva "versatilidad" de los "modelos matemáticos" en que se apoyan (14) sino porque con la aplicación mecánica de la ecuación rango-tamaño tendríamos que reconocer en el Jaén de la Edad del Cobre una metrópolis imperial, con un área amurallada 5 veces mayor que la de Los Millares, considerado el núcleo mas complejo de cuantos se conocen en los ámbitos mediterráneo y atlántico.

(13) Fuera de este ámbito el círculo preside desde la aldea Borobo de Lévi-Strauss hasta los proyectos futuristas de arquitectos visionarios como Boulle; paisajes funerarios (cromlech, henges, thóloi, túmulos megaliticos); ciudades como Aquisgrán, Bagdad, Pavía, Norlingen, la Roma de Rómulo, la Roma medieval, además de sueños y utopías: la atlántida, los proyectos de falansterios, las representaciones de la ciudad de Dios, etc.

(14) Una recopilación comentada de sistemas teóricos de cálculo de población puede consultarse en Gracia et alii 1996.

T. P., 56, n. ${ }^{\circ} 1,1999$ 
Semejante tamaño reclama una parcelación intermedia entre los complejos domésticos y el poblado, pero en ZAMB 3 queda pendiente la determinación de los rasgos visibles en que se expresen esos agregados. Sólo podemos avanzar la existencia de la estructura de paredes rectilíneas de la parcelaE1E3 que podría entenderse como un hito aglutinante de complejos domésticos. Nos conformamos por ahora con plantear una compartimentación interior incuestionable: las coronas (espacios inter-fosos). Los cinco fosos definen 4 coronas mas el círculo central. Hasta la fecha no se han comprobado diferencias arquitectónicas o funcionales significativas entre las tres coronas intramuros, aunque, como se ha comentado mas arriba, la cuarta corona tendría un uso agrícola marcado y el espacio central podría deparar sorpresas, por ello en este punto es mejor encomendarse a futuras investigaciones.

El sistema de fosos está amortizado cuando se construyen los complejos domésticos cercados de ZAMB 4. Sin embargo la extensión del asentamiento es la misma y se mantiene la fortificación como se comprueba en la estratigrafía de la parcela E 24 de la UA 23 (Fig. 5).

A diferencia de ZAMB 3, en ZAMB 4 sí se reconocen elementos de vertebración supra-doméstica. La delimitación física de los complejos domésticos impone un división del asentamiento en "calles" de trazado irregular, ancho variable y firme poco cuidado (E 2-4 y E1-E3 de la UA 23; Manzana $\mathrm{E}$, manzana $\mathrm{H}$ y trinchera del ferrocarril). Los complejos se encuentran rodeados por "calles" donde se aprecian los estragos de los regueros y los restos de detritus, con alguna intervención "urbanística" como escalones para salvar desniveles o canalículos para encauzar las aguas (E 2-4 de la UA 23).

En la parcela E 2-2 de la UA 23 se ha detectado una estructura rectangular con evidencias de procesos de trabajo textil. La diferenciación morfológica se acentúa mediante la construcción de un pasillo de acceso que desemboca en la puerta junto a la cual, en el interior, se han recogido un buen conjunto de pesas de telar. El edificio contenía varios recipientes de almacenaje. En lamanzana E del RP 4 también se han documentado construcciones cuadrangulares y en la parcela E 2-6 de la UA 23 existen tramos de muro rectilíneos que podrían asemejarse a los citados. Hemos interpretado estos espacios como elementos estructurantes de sectores mas extensos que agruparían varios complejos y a los que asociamos, convencionalmente, con linajes (Hornos et alii, 1998: 86). A pesar de ello las construcciones cuadrangulares no bastan per se para discriminar un nuevo eslabón social entre la comunidad y la unidad doméstica. También podrían formar parte de una unidad doméstica destacada o de un espacio comunitario. Sin embargo hay que hacer notar que no es el tipo constructivo habitual.

Otra diferenciación funcional se documentó entre el segundo y tercer foso (Manzana E del RP 4 ). Se trataba de una concentración de escorias de cobre, que no pudo ser excavada al localizarse bajo áreas no edificables. Su adscripción a esta fase es dudosa, pudiendo asociarse a ZAMB 3. Asimismo se han documentado materiales reconocidos como crisoles por sus excavadores, junto al cuarto foso, en las parcelas E 2-4 y E 2-6 en un contexto doméstico (Fig. 4). Confiamos en que estas primeras interpretaciones de la organización del espacio intramuros se vean pronto superadas por otras fundamentadas en los estudios en marcha. Por su parte el escenario extramuros cambia notablemente entre ZAMB 3 y ZAMB 4. Por un lado comenzamos a barajar la hipótesis de que la necrópolis de cuevas artificiales de Marroquíes Altos situada 500 m. al sur del recinto amurallado pertenezca a esta fase. Los ajuares rescatados durante las excavaciones de los años 50 así parecen atestiguarlo y de hecho fueron fechados por su excavador en "la transición del Calcolítico al Bronce" (Espantaleón, 1957: 169), siendo incluidos por Ruiz et alii (1986: 281 y 282) en lo que denominan "Bronce del Piedemonte" viendo en ellos un ejemplo del proceso de estratificación social que desembocará en los ritos de enterramiento individuales (15). Por otra parte el área de cultivo debería estar parcelada como el interior del poblado, y el quinto foso estaría abandonado, sustituyéndose por una red de acequias y pozos menos organizada. Este planteamiento, basado en la hipótesis de un proceso de particularización de la economía del poblado, se contrastará con excavaciones en el sector RNP 1.

Ese proceso tiene como efecto colateral la dispersión poblacional que planteamos como explicación de la situación de la ZAMB en la fase 5. En el vial A-A' del RP4 se ha excavado un enterramiento individual en pithos con un ajuar adscribible a un Bronce Pleno, y otro en cueva artificial con materiales similares.Ambos se encuentran en un sector sin

(15) Estos ritos requieren un "tiempo de adopción" y en lugares como Baeza (Jaén), en plena Edad del Bronce el tipo de enterramiento mas común es el familiar o de pareja (Zafra y Pérez, 1992: 300). Esto podría indicar que la familia se instituye como unidad social autónoma, lo que proponemos como indicador de la existencia de relaciones sociales campesinas. 


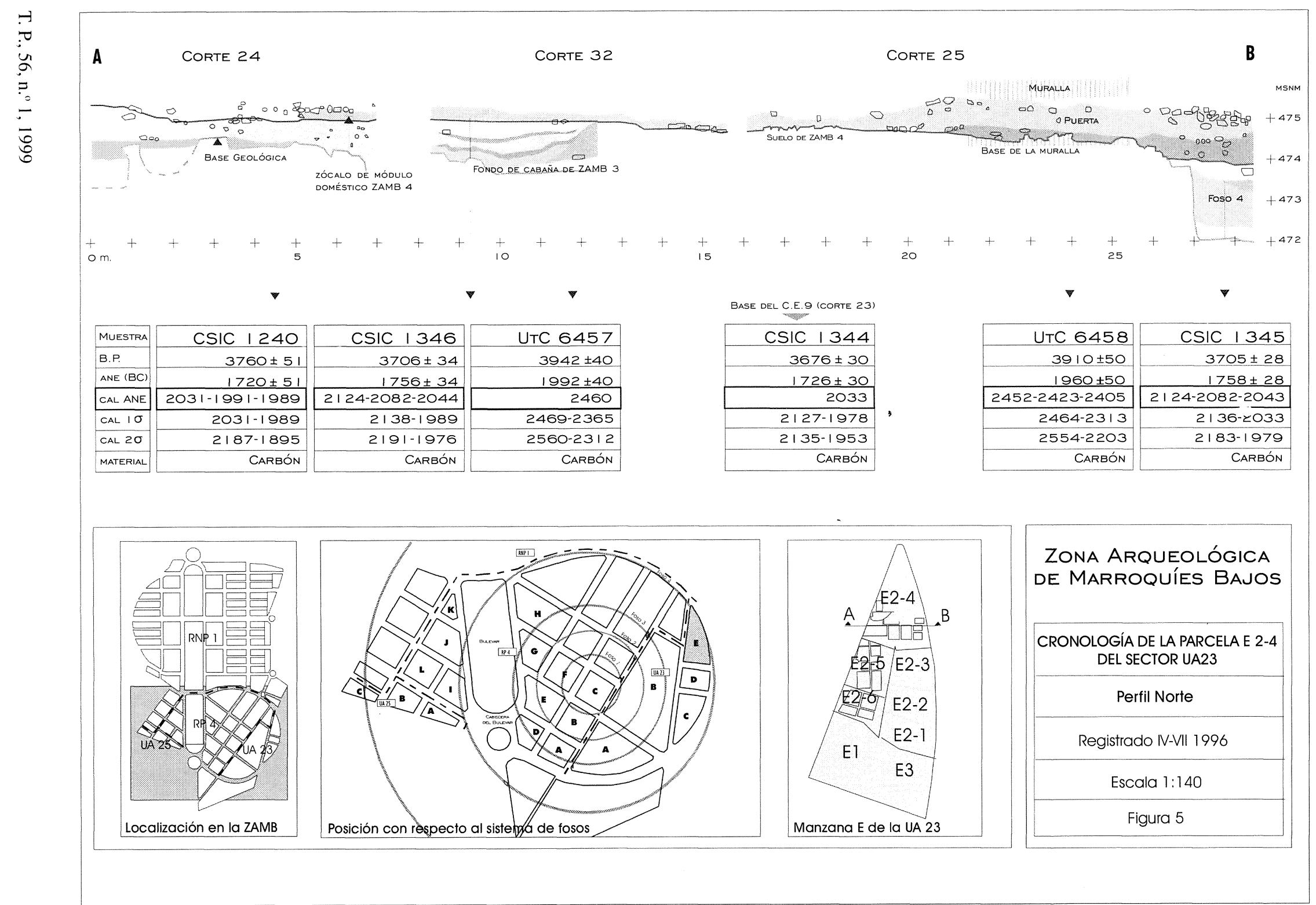

Fig. 5. 
excavaciones extensas por lo que sólo nos atrevemos a apuntar la posibilidad de una ocupación dispersa en núcleos mas o menos reducidos a lo largo del piedemonte hacia el segundo cuarto del segundo milenio (calibrado). La hipótesis puede apoyarse en la detección de restos adscritos a este momento en la zona alta de la ciudad (Serrano y Esteban, 1997) o en el Cerro del Castillo de Santa Catalina.

\subsubsection{Intensificación agraria y campesinización}

Asumiendo nuestra actual ignorancia sobre las causas del origen del asentamiento (ZAMB 2-3-4) vamos a exponer nuestro punto de vista sobre la evolución del mismo una vez producida la concentración poblacional. Sabemos que las causas de los cambios no deben buscarse necesariamente en el proceso productivo, pero en esta ocasión estamos convencidos de que es ahí donde reside la explicación. Las intensificación de la producción agraria que supone la construcción del sistema de canalización, delimitación y defensa (medio de trabajo construido en ZAMB 3) y la nueva organización social que deviene de esa apropiación colectiva de la tierra y su posterior parcelación familiar (campesinización en ZAMB 4) están en su origen.

LaZAMB no es un texto autocontenido, no es un contexto explicable per se. Las interpretaciones adaptativas son puestas a prueba por la variedad de formas de explotación y de tenencia que se aplican a un mismo medioambiente. Esto es importante para comprender la lógica del asentamiento ¿Por qué ahí?, ¿Por qué entonces? La cuestión del origen suele despacharse con llamadas de atención sobre los recursos que actúan como reclamo. En este punto conviene recordar que el término 'recursos' hace referencia a una expectativa de uso, a una potencia de la tierra, su empleo descuidado puede alejarnos del verdadero factor que posibilita aquí el asentamiento: la producción a gran escala del medio de trabajo. Canales, balsas, terrazas de cultivo, etc. domaron el cono de deyección de los cursos de agua del cinturón de montañas de la ciudad de Jaén (Lám. I). Una tarea ingente cuyo fin último era garantizar el futuro de la población concentrada y asegurarse el dominio sobre el agua (16), recurso garante de ese futuro y, sin control, amenaza para el mismo.

La concentración de población impone nuevas

(16) "Allí donde podía controlarse el agua, podían controlarse los vegetales y los animales. Además dado que plantas y animales eran la principal fuente de energía, el control sobre el agua significaba el control sobre la energía" (Harris, 1987: 258). formas de aprovechamiento del espacio del poblado que incluye la ocupación de áreas donde la construcción subterránea es imposible. La asignación de parcelas específicas a las unidades domésticas necesita de nuevas técnicas que permitan la remodelación del espacio, muy problemática en los complejos subterráneos que se multiplican ocupando nuevos terrenos. Esa tradición constructiva milenaria se sustituye por edificios de superficie, primero con cimentaciones de madera y después de piedra. Estos cambios podrían explicarse como ensayos adaptativos hasta la obtención de un modelo de vivienda adecuado a las condiciones ambientales del sitio (17). Sin embargo éste no es un proceso puntual ni puede explicarse desde Marroquíes Bajos, de hecho la sucesión hoyos de poste-zócalos de piedra está tan extendida que se ha interpretado como una de las bases para detectar el cambio cultural entre el Neolítico Final y la plena Edad del Cobre (Arteaga, 1992: 193).

De cara a la producción agraria esa concentración precipita formas de aprovechamiento intensivas. Esto contradice la opinión de Carnerio (1988: 27) que propone que la concentración de recursos provoca el "inicio de la presión demográfica". Mas bien cabría defender que la puesta en producción de la red hidrológica tal y como la entendemos exige con carácter previo una concentración poblacional y por tanto sería premisa y no consecuencia de la concentración de recursos.

En efecto la gran hidráulica prehistórica se instala sobre un relieve abarrancado y tortuoso con desniveles fuertes y pendientes abruptas junto a lomas redondeadas y laderas suaves. En muchos puntos la profundidad de los suelos arcillosos apenas alcanza unos centímetros sobre la base geológica margosa y estéril, sólo la abundancia de agua y las cubetas sedimentarias de las tierras bajas mejoran las perspectivas productivas. Por tanto no es tan evidente que se perciba una concentración de recursos suficiente para el sostenimiento de una población considerable. Esto sólo podría plantearse en caso de disponer de conocimientos técnicos adecuados y una importante capacidad de inversión de fuerza de trabajo.

En todo caso la concentración de recursos, aún provocada, puede ayudarnos a explicar por qué el asentamiento esta ahí y no un poco a la derecha o

(17) Las estructuras subterráneas no son la mejor solución en suelos inundables y las de cimentación orgánica son muy sensibles al agua y al barro por lo que las de piedra podrían ser la solución frente a condiciones ambientales cambiantes. 
algo mas arriba, sin decirnos nada sobre por qué se construye entonces y no antes o después, siendo la respuesta a esta pregunta básica para comprender su evolución histórica. Sin embargo ninguna de las opciones que se ofrecen nos satisface plenamente. Estamos lejos de poder demostrar que la presión demográfica sea la causa del cambio, como ha defendido Lull (1983: 426) para el Sureste. Tampoco confirman los datos que sea consecuencia del "poder coercitivo y organizador de una autoridad central" (Renfrew y Bahn, 1995: 200) y menos que sea una especie de "desarrollo natural" del poblamiento en las zonas potencialmente regables, por mucho que las generalizaciones dominantes indiquen que, en éstas, la población no se encuentra concentrada, sino que "se dispersa en viviendas aisladas construidas al lado de los terrenos de cultivo" (García, 1976: 104) frente a la "forma de asentamiento general de los pueblos agricultores de secano [que] es concentrada, quedando los terrenos cultivables fuera del núcleo habitado".

La causa externa sin ser descartable tampoco nos satisface. De hecho en la fase ZAMB 3 al tiempo que el sistema de riego se construye la fortificación. Nocete (1989 y 1994) ha propuesto una teoría sobre el origen del Estado en elAlto Guadalquivir, en la que, en el momento de construcción del sistema de fortificación y regadío de Marroquíes Bajos (mediados del tercer milenio en fechas calibradas), se está produciendo la creación de un "territorio político plurilocal" (Nocete, 1994: 310-320), un proceso de concentración poblacional e intensificación agraria que según él obedece al desarrollo de un conflicto territorial (Nocete, 1994: 315). De este modo nos situaríamos del lado de Meillassoux (1987: 58) para quién "la conciencia de una relación exclusiva con una porción del suelo no procede del movimiento de exploración y de ocupación de las tierras ni del trabajo invertido por los miembros presentes y pasados del grupo. Sólo surge si el usufructo de esa tierra es amenazado por otra colectividad". Si esto es así (18), el cambio en la relación con el medio de producción procedería de una causa externa. Confesamos que esta eventualidad no la habíamos contemplado a priori, pero admitimos no sólo que es históricamente posible sino que ha sido muy frecuente (19).

(18) La cautela es necesaria ya que la tesis de Meillassoux se apoya en su estudio de los sistemas económicos africanos tal y como los conoció en los años sesenta.

(19) En los últimos 2000 años la ZAMB ha pasado a formar parte de 5 imperios (romano, visigodo, Omeya, Almohade y castellano), la política exterior de las grandes formaciones sociales
Ante esto debemos admitir que, al día de hoy, no contamos con base suficiente para optar por una explicación sólida al respecto. Lo que sí sabemos es que la construcción de los complejos domésticos cercados coincide con el abandono de los macrosistemas de riego, cosa que se interpreta como que una primera fase de cooperación a gran escala para la construcción y mantenimiento de la red de irrigación (para la producción de los medios de trabajo) fracasa y se impone una forma de explotación familiar que, manteniendo la unidad del asentamiento y por tanto de la comunidad, favorece el reparto de tierras.

A la escala intra-asentamiento y desde una perspectiva adaptativa la causa del fracaso del modelo podría buscarse en la presión sobre el entorno inmediato que supone una población de este tamaño y que provocaría, por ejemplo, la desforestación del Cerro de Santa Catalina. Los episodios de erosión subsiguientes podrían explicar la fase de acreción sedimentaria localizada entre ZAMB 3 y ZAMB 4 , especialmente significativos en la parcela $15 \mathrm{~J}$ de la manzana A del RP4 y en la cabecera del bulevar. Como efecto del descuido de la red hídrica cambian los procesos naturales de formación del sitio. Los aportes sedimentarios son mucho mayores al eliminarse el efecto barrera de los fosos y el agua comienza a inundar zonas hasta ese momento secas (bulevar). En poco tiempo se crea un medio húmedo con zonas palustres favorecidas por la relativa libertad de movimientos de los cursos de agua y la elevación del nivel freático consecuencia del abandono de los canales de irrigación y drenaje. Esa hipótesis inicial se apoya por un lado y como se ha comentado mas arriba, en la documentación de grandes depósitos de aluvión achacables a un régimen fluvial violento entre ZAMB 3 y 4 ; y por otro lado en los primeros estudios palinológicos (20) que han

mediterráneas y los movimientos de tropas subsiguientes han afectado decisivamente al modelo de dominación impuesto en ese apartado rincón del interior de Andalucía. Con anterioridad a la colonización romana tenemos ejemplos costeros de colonizaciones que se rastrean hasta principios del primer milenio, pero la reacción antidifusionista en Prehistoria es tan fuerte que nos resistimos a ver guerras de conquista y políticas imperiales donde las fuentes escritas no las avalan. Pese a los esfuerzos de Carneiro o Stocker lo que podrían ser tributos siguen figurando como "intercambio" o comercio. Esto no impide que haya autores para los que el mundo argárico bien podría ser un estado expansionista (un imperio), y admiten el carácter de tributo de algunos items arqueológicos (Contreras et alii, 1997: 140). También se atisba una rebelión contra el autoctonismo alentada por las instituciones europeas empeñadas en ennoblecer su origen (Mederos Martín, 1995: 131-141).

(20) Estudios inéditos realizados por Pilar López, José Antonio López-Sáez y Rosario Macías del Laboratorio de Arqueobotánica del Centro de Estudios Históricos del CSIC, Madrid. 
dado como resultado una vegetación asociada a ambientes húmedos (sauces, abedules, lenteja de agua) que se hace dominante al menos en el borde noreste de la zona arqueológica a partir del $2100 \mathrm{cal}$. ANE (ZAMB 4).

Sin embargo ese fenómeno no se produciría si el sistema de fosos estuviera en funcionamiento. El abandono de su mantenimiento sería anterior a ese proceso erosivo y tendría su causa en la reordenación de los objetivos socioeconómicos de la comunidad y no en fenómenos naturales. Vemos en ello una consecuencia de lo que llamamos proceso de campesinización.

Está extendida una "imagen neolítica" de comunidades campesinas igualitarias con una economía de subsistencia que evolucionan hacia formas más o menos complejas de sociedades tributarias. Ese escenario comienza a ser discutido. Se cuestiona el propio significado del término 'Neolítico' con su carga tradicional de límites cronológicos, tecnológicos y sociales (Montero y Ruiz, 1996); se cuestiona el carácter igualitario en las relaciones sociales para el Neolítico en el Alto Guadalquivir (Lizcano et alii, 1991-1992), o en Cataluña (Blasco et alii, 1996); y, lo que es mas importante para este trabajo, se discute la existencia del campesino neolítico, proclamando que el campesinado es la culminación de la revolución neolítica, "siendo la consolidación del primer campesinado la principal característica histórica del Calcolítico y la Edad del Bronce" (Díaz-del-Río, 1995:104) (21).

Esta afirmación es fundamental y contraviene la hipótesis de que la "aparición del Estado señala la transición entre productores primitivos de alimentos y campesinos" (Wolf, 1975: 21-22). Para Wolf la producción de un "fondo de renta" destinado al pago del tributo distingue al agricultor primitivo del campesino. Estamos seguros de que para que haya Estado tiene antes que haber campesinos a los que explotar, lo contrario no siempre es cierto ni, por supuesto, necesario. Por tanto, cualquier teoría sobre el origen del Estado, o incluso sobre el origen de la desigualdad en las sociedades agrarias, pasa por la proposición de una teoría sobre el origen del campesinado.

Planteamos que la jerarquización puede ser en su inicio una consecuencia de la movilidad centrífuga

(21) Consecuencia de la "total maduración" de lo que Lumbreras (1988: 352) denominó "modo de producción neolítico" caracterizado por el desarrollo de los medios de producción de alimentos. del campesinado (22), es decir de la diferencia de riqueza entre unidades domésticas fomentada por su operatividad autónoma. Explicaría a la vez la aparición de los privilegios heredados, transmitidos naturalmente en el marco de los modos de descendencia de las unidades domésticas campesinas. Si estamos en lo cierto podríamos estar describiendo uno de lo procesos que desembocarían en la institucionalización de la desigualdad política. El derecho a la apropiación de la tierra y la consolidación de la familia (nuclear, extensa o múltiple) como unidad económica autónoma (23) dentro del asentamiento (la unidad de producción-reproducción ya no es la comunidad), va diluyendo los lazos de parentesco fuera de ella, lazos que son sustituidos en parte por formas mas o menos desarrolladas de relaciones de clase, que serán dominantes a partir de entonces (24).

Pocos arqueólogos se han planteado las implicaciones teóricas, metodológicas e históricas que se desprenden del uso del término 'campesino' (25), quedando extendida la fórmula productor agrícola de subsistencias $=$ campesino. Se da por ello una amplia gama de categorías asociadas a las comunidades campesinas, incluso dentro de una misma corriente teórica, se habla de modo de vida campesino, modo de producción campesino e incluso formaciones sociales campesinas. En la mayoría de los casos esta confusión se debe a una utilización intuitiva de un concepto cuya definición no acaba de ser aquilatada pese a una tradición de estudios muy amplia y especialmente fructífera en Economía, Sociología, Antropología e Historia Contemporánea, o quizás por ello.

En arqueología prehistórica uno de los escasos usos reflexivos del término la hallamos en Vicent que sitúa a la sedentarización como una característica definitoria de las primeras "sociedades campe-

(22) Se utiliza el término 'movilidad' 'en el sentido que le da Shanin (1983: cap. 4): desigualdad de riqueza en el tiempo.

(23) Esto parece contradecir la hipótesis de que la autonomía de la familia sea propia del llamado Modo Doméstico de Producción (Shalins, 1977; Gilman, 1991: 20), pero en realidad se plantea a una escala diferente. La autonomía campesina en su origen se produce dentro de la comunidad y frente a ésta, la autonomía de las comunidades domésticas de Sahlins se expresa frente a otras comunidades.

(24) No defendemos que la movilidad centrífuga y el enfrentamiento entre unidades domésticas campesinas y comunidad suponga la anulación de ésta, ya que lo que se produce es su afirmación-negación, a causa de la reciprocidad de base parental persistente (Díaz-del-Río, 1995: 105).

(25) Las tesis procesualistas prefieren términos como policultivo ganadero (Harrison y Moreno, 1985) o revolución de los productos secundarios (Sherratt, 1981), para referirse a práctica productivas típicamente campesinas. 
sinas". Para él la construcción de la 'aldea' (frente al 'campamento') como lugar estable de producción y reproducción y la conversión permanente del entorno en un agrosistema es lo que hace de sus habitantes un "grupo campesino". La vinculación a la tierra, la creación de lo que denominamos infraestructura de dependencia, se presenta como la "trampa agrícola" (Vicent, 1991b: 45) que establece las condiciones para una coacción extraeconómica facilitada por el miedo a perder la inversión realizada en la tierra. Díaz-del-Río (1995: 106, 107) ha planteado para el Calcolítico y la Edad del Bronce en la Meseta la existencia de un sistema de explotación campesina basada en la explotación agroforestal, al que denomina "gestión pluriactiva del ecosistema". Este sistema sería la "forma meseteña" (Díaz-del-Río, 1995: 107) de la intensificación agraria definida como revolución de los productos secundarios.

De estos autores interesa destacar el enfoque histórico de la descripción del campesinado, no plantean una caracterización exclusivamente analítica o sociológica, inciden en aspectos como el cambio en las estrategias económicas que son determinantes en la detección de modos de vida campesinos. En efecto no todas las sociedades agrarias de subsistencia son comunidades campesinas. Nos referiremos a las sociedades de productores primitivos de alimentos de Wolf como paleoagrarias para diferenciarlas de las campesinas a las que consideramos consecuencia de una forma de explotación especializada y evolucionada de aquellas. Desde esta óptica los modos de vida campesinos son una consecuencia del proceso histórico de particularización de los medios de producción, que en la Prehistoria Reciente se inicia con los instrumentos, continúa con el ganado y la fuerza de trabajo y finaliza con la tierra. Una vez que todos estos elementos son puestos a disposición de la unidad doméstica se institucionaliza la casa campesina con $s u$ espacio de residencia y reproducción, sus posesiones (ajuar doméstico, instrumentos, subsistencias, objetos de prestigio, etc.), su parcela de tierra y $s u$ ganado (26).

Es notorio que esta institución (la casa) aglutina los distintos recursos cuyas apropiaciones exclusivas se plantean como vías de desarrollo de la desigualdad entre el Neolítico y la Edad del Bronce

(26) No es la propiedad de los elementos sino la posibilidad de acceso a los mismos lo que queremos significar con la relación de pertenencia que indica el pronombre "su"; el matiz es importante para determinar la desigualdad entre las unidades domésticas campesinas.
(Gilman, 1997: 88-89): la tierra, el ganado, o el metal. Puede ser que todos esos elementos hayan ido escapando de la organización segmentaria de la propiedad, pasando a la esfera de dominio familiar. En todo caso entendemos la particularización como un proceso de transferencia del control de los medios de producción (fuerza de trabajo, ganado, subsistencias y tierra) desde la comunidad hacia las unidades domésticas, dándose la circunstancia de que paralelamente se fomenta la diferenciación social entre ellas, consecuencia lógica de la disolución de los mecanismos de reequilibrio de la comunidad.

Lacampesinización es la primera consecuencia de ese proceso de particularización de los medios de producción, pero no la única, puesto que es en esa coyuntura en la que se puede dar la apropiación de trabajo excedente recaudable como "renta de la tierra" (Vicent, 1991: 33), plustrabajo creado y legitimado por las propias estrategias de supervivencia campesinas mediante la autoexplotación de la unidad doméstica. La vinculación exclusiva con la parcela de tierra, sumada a la inversión en sistemas de cultivo costosos o de rendimiento diferido (terrazas, canales, frutales, etc.), crea una infraestructura de dependencia (27), que precipita el reconocimiento de élites violentas protectoras. Con la aparición de un modo de vida campesino está dado el paso para la consolidación de las relaciones de explotación permanentes en esta zona del Alto Guadalquivir.

En las comunidades campesinas la casa y la tierra siempre han determinado la condición social, el acceso diferencial a la tierra como causa de la desigualdad de la riqueza y la casa como evidencia/ consecuencia de esa desigualdad. Si somos capaces de demostrar un acceso diferencial a la riqueza, y eso podremos hacerlo con la comparación entre casas, estaremos en condiciones de plantearnos la existencia de una comunidad jerárquizada y los términos en que se apoya la jerarquización. De este modo el hecho de que casa y tierra sean riquezas portadoras de estatus podrá desligarse de la contraposición engañosa entre los dominios "del uso y la transmisión" y los de la "adquisición y la propiedad" que en ocasiones parecen deslindar en el tiempo las relaciones impuestas por el parentesco de las atribuibles a la esfera política (Leduc, 1992: 276). En las sociedades como la que investigamos esto no es una cuestión de "avance" de la complejidad. No

(27) No es una dependencia ecológica, sino socioeconómica: el miedo a perder la tierra y el trabajo invertido en ella hace que no vacilen en ofrecer parte de su trabajo a cambio de seguridad.

T. P., 56, n. ${ }^{\circ} 1,1999$ 
creemos que el parentesco sea una etapa de organización social previa a la política, sino dos conjuntos de relaciones establecidas a escala diferente. El primero fija históricamente los comportamientos, derechos y deberes dentro del grupo doméstico, el segundo entre grupos. En este sentido nos parece mas apropiada la propuesta de Castro et alii (1996: 38) que, en su formulación de una teoría de las prácticas sociales, distinguen entre prácticas socioparentales y socio-políticas para no confundir las situaciones de diferenciación sexual (explotación dentro de la familia) con las de disimetría social promovidas por prácticas políticas.

Eso no es obstáculo para que la forma que adquieren las relaciones de explotación dentro de la comunidad (id est entre unidades domésticas) esté basada en las vías ensayadas con éxito para la explotación de la fuerza de trabajo dentro de los grupos domésticos y se institucionalicen modelos de explotación paternalistas comparados por algunos autores con relaciones de protección "mafiosa" (Vicent, 1991: 34).

Pero ¿cómo se produce este proceso? Algunos caracteres que conforman y reproducen a la comunidad parental, como su estructuración en grupos familiares, adquieren nuevas funciones no previstas ni contempladas, como explotar la tierra para la familia y no para la comunidad, que acaban desarrollando nuevas relaciones sociales. Esa divergencia funcional serviría para explicar la forma en que se producen los cambios, las causas habría que buscarlas a mayor profundidad. Meillassoux (1987: 121) cree que para que se produzca una transformación radical en el seno de lo que llama "sociedades domésticas" (bandas y tribus) es necesaria una "disociación de los ciclos productivo y reproductivo", que se da cuando los individuos quedan ligados a su familia de origen, y su movilidad dentro de la comunidad es sustituida por el movimiento de los productos, abriendo el camino a la acumulación desigual. Admitiendo que en las primeras ocupaciones de la ZAMB podemos reconocer una sociedad segmentaria, sostenemos que la disociación de Meillassoux y la consiguiente campesinización se está produciendo en Marroquíes Bajos a finales del tercer milenio. A la trascendencia de este cambio hay que hacerle dos precisiones, una, para no ocultar las repercusiones sociales de la diferenciación sexual (Castro et alii, 1996: 36), que los "individuos que se mueven" son las mujeres, que a menudo también acompañan a los productos que se mueven (dotes o herencias de la novia) y dos, que es en el marco de la explotación del trabajo (en la unidad doméstica y entre unidades) y no en el del intercambio (de productos o mujeres) donde se origina la desigualdad. Porque tal intercambio está institucionalizado para preservar y transmitir los desequilibrios de riqueza y por tanto consolida la desigualdad.

Con este bagaje en la macro-aldea las relaciones de propiedad y pertenencia territorial imponen dos alternativas: dispersión o transformación en ciudad. En este caso se produce la dispersión, quizás porque los modos de vida campesinos están especialmente dotados para sostenerse en pequeñas comunidades de aldea como lo demuestra el hecho de que subsistan bajo los mas dispares modos de producción (desde el esclavista al capitalista). De aquí se desprende que si no hay campesinos no hay ciudades, al contrario de lo que postulaba Redfield (en Shanin, 1983: 291) para quien no hay campesinado antes de la primera ciudad.

El hecho es que en torno al siglo XX-cal. ANE el asentamiento con las características de tamaño y estructura conocidas desaparece y lo hace súbitamente: se produce un colapso. Con los datos actuales el sistema de complejos domésticos cercados se desarticula tras tres o cuatro generaciones siendo el asentamiento abandonado como atestiguan la localización in situ de ajuares domésticos y herramientas valiosas (E 2-4; E 2-5, E 2-6 de la UA 23; G, E, bulevar del RP 4). La estructura que había durado 300 ó 400 años con las relaciones de producción de la comunidad segmentaria se desmorona en algo mas de un siglo con estas nuevas formas de explotación.

Podemos pensar que la causa del colapso es interna de modo que la contradicción entre el mantenimiento de las formas establecidas de integración social, que exigían importantes contribuciones de trabajo comunitario, y los nuevos objetivos de reproducción social y económica de las unidades domésticas, hicieron saltar la base económica sobre la que se sustentaba ZAMB 3 provocando la disgregación de la comunidad y posteriormente la dispersión.

Pero no hay que olvidar que parte de las fechaciones publicadas del asentamiento argárico de Peñalosa (Baños de la Encina, Jaén), c. 2065-2025 cal. ANE (Castro et alii, 1996: apéndice VI, basadas en los datos de Contreras et alii, 1991: 235) son contemporáneas de la ZAMB 4, encuadrándose en lo que Castro et alii (1996: 124-125) denominan Argárico II, fase con cronología entre 2050 y 1960 cal.ANE, interpretada como un proceso de expan- 
sión desde el sureste hacia las regiones interiores. Tambien hay que tener en cuenta que coincide con la fases VI-VII de la transición al Estado postulada por Nocete (1994: 320 y ss.) para la Cultura de las Campiñas c. 2200-1900 cal.ANE caracterizada por la transformación del "territorio cónico plurilocal" en "territorio de coerción supralocal". Es decir, si estos autores están en lo cierto, los asentamientos del piedemonte como Marroquíes se encuentran constreñidos en torno al $2000 \mathrm{cal}$. ANE por la pujanza de dos formaciones sociales en expansión: la de las Campiñas delAlto Guadalquivir y la de El Argar.

De una u otra forma el movimiento histórico de particularización de los medios de producción y los objetivos de reproducción de las unidades domésticas establecen las circunstancias que posibilitan una explotación permanente e institucionalizada. La clave para determinar el alcance de esta explotación y la consiguiente desigualdad social está en la transformación de las relaciones de propiedad y su estudio es, pese a la dificultad que entraña, necesario para comprenderla. Puede que en este asentamiento estemos en disposición de evaluar estas relaciones en y entre unidades domésticas, desde lo que Gilman (1997: 86 y 89) denomina en los análisis de los sistemas de propiedad, el "enfoque abajo-arriba" por contraste con el "enfoque arriba-abajo", mas común, que examina las estrategias de financiación de gastos y riqueza de las élites.

\section{EPÍlOOGO}

A nadie se le escapa que la ZAMB contiene una serie de indicadores cuya interpretación ha sido muy distinta de la que aquí planteamos. Sus dimensiones, las murallas, las redes de canales, o las "infraestructuras urbanísticas" son recurrentemente consideradas evidencias de jerarquización territorial y desigualdad social. Para ser sinceros nuestro planteamiento, aparte de ser consistente con la información que hemos procesado, está mediatizado por el convencimiento ideológico de que las teorías que insisten en la aparición temprana de la jerarquización o de las clases sociales, contra la intención de muchos de sus defensores, contribuyen a promover el supuesto carácter "natural" de la desigualdad.

La coherencia con la escala de la investigación impide por ahora abordar con la suficiente profundidad la proyección territorial del proceso, ámbito en el que se podrán contrastar las hipótesis aquí vertidas. Mientras tanto esperamos que esta visión del interior del asentamiento haya contribuido a situar los términos de una discusión que con el tiempo permita resolver el problema histórico planteado, porque como reconoció Larry Laudan (1978: 66) "el problema resuelto (empírico o conceptual) es la unidad básica del progreso científico".

\section{AGRADECIMIENTOS}

Queremos expresar nuestro agradecimiento a Felipe Criado y Antonio Gilman por sus comentarios y críticas a pie de obra y muy especialmente a Maribel Martínez Navarrete por su interés y aliento constante.

\section{BIBLIOGRAFÍA}

Arteaga Matutes, O. (1992): "Tribalización, jerarquización y estado en el territorio de el Argar”. Spal, 1: 179208.

Assmann, J. (1995): Egipto a la luz de una teoría pluralista de la cultura. Akal. Madrid.

Bestard CAmps, J. (1991): "La familia: entre la Antropología y la Historia”. Papers, 36: 79-91.

Blasco, A.; Villalba, M.J. y Edo, M. (1997): "Aspectos sociales del Neolítico Medio catalán”. En R. Balbín y P. Bueno (ed.): II Congreso de Arqueología Peninsular. Zamora 1996, II. Fundación Rei Afonso Henriques. Zamora: 89-99

Clarke, D.L. (1972): “A provisional model of an Iron Age Society and its settlement system".En D.L. Clarke (ed.): Models inArchaeology. Methuen. Londres: 801869.

Carneiro, R.L. (1988): "Reflexiones adicionales sobre la concentración de recursos y su papel en el surgimiento del Estado". En L. Manzanilla (ed.): Coloquio V. Gordon Childe. Estudios sobre la revolución neolítica y la revolución urbana. Universidad NacionalAutónoma de México. México: 265-281.

Castillo Armenteros, J.C. (1997): La Campiña de Jaén en época emiral. Universidad de Jaén. Jaén.

Castro López, M. (1989): "De Cesar a Teodosio (49 a.C. - 395 d.C.)”. En J. Fernández (dir.): Jaén, II. Editorial Andalucía. Granada: 423-441.

Castro, P.V; Colomer, E.; Chapman, R.W.; Gili, S.; GonZÁlez Marcén, P.; Lull, V.; Micó, R.; Montón, S.; PICazo, M.; Rihuete, C.; Risch, R.; Ruiz ParRa, M.; SAnauja Yll, M.E. y Tenas, M. (1992): "Proyecto: Gatas. Sociedad y economía en el sudeste de España c. 2.500-800ANE”. En Investigaciones arqueológicas en

T. P., 56, n. ${ }^{\circ} 1,1999$ 
Andalucía 1985-1992. Proyectos. Consejería de Cultura de la Junta de Andalucía. Huelva, 1992: 401-415.

CAstro Martínez, P.V.; Lull, V. y Micó, R. (1996): Cronología de la Prehistoria Reciente de la Península Ibérica y Baleares (c.2800-900 calANE). B.A.R. International Series 652. Tempus Reparatum, Oxford.

Contreras Cortés, F.; Nocete Calvo, F.; Sánchez Ruiz, M.; Lizcano Prestel, R.; Pérez Bareas, C.; Casas Garrido, C.; Moya, S. y Cámara Serrano, J.A. (1991): " $3^{a}$ campaña de excavaciones en el poblado de la Edad del Bronce de Peñalosa (Baños de la Encina, Jaén)". Anuario Arqueológico de Andalucía/1989, II: 227-236.

Contreras Cortés, F.; Rodríguez Ariza, O.; Cámara SeRRANo, J.A. y Moreno OnORato, M.A. (1997): Catálogo de la exposición Hace 4000 años... Vida y muerte en dos poblados de laAltaAndalucía. Consejería de Cultura de la Junta deAndalucía y Fundación Caja de Granada. Granada.

CHANG, K.C. (1976): Nuevas perspectivas en arqueología. Alianza. Madrid.

Chouquer, G. (1996): "Parcellaires et longue durée. Points de repére historiques et problémes d'interprétation". En Gérard Chouquer (dir.): Les formes du paysage. Tome 2 - Archéologie des parcellaries. Actes du colloque d'Orleans (1996). Éd. Errance. París.

DíaZ-DEL- Río EsPaÑol, P. (1995): "Campesinado y gestión pluriactiva del ecosistema: un marco teórico para el análisis del III y II milenios A.C. en la Meseta peninsular". Trabajos de Prehistoria, 52(2): 99-109.

EsPANTALEÓN, R. (1957): "La necrópolis eneolítica de Marroquíes Altos". Boletín del Instituto de Estudios Giennenses, 13: 165-175.

FERnÁndez Gómez, J. y Oliva Alonso, D. (1985): "Excavaciones en el yacimiento calcolítico de Valencina de la Concepción (Sevilla). El corte C (La Perrera)", Noticiario Arqueológico Hispánico, 25: 7-131.

Fernández-Posse, M. ${ }^{\mathrm{a} D}$.; Gilman, A. y Martín, C. (1996): "Consideraciones cronológicas sobre la Edad del Bronce en la Mancha". Complutum Extra, 6 (II): 111-137.

García, J.L. (1976): Antropología del territorio. Taller de Ediciones J.B. Madrid.

Gilman Guillén, A. (1991): "Condiciones sociales bajo las cuales el cambio tecnológico es la causa inmediata de la evolución cultural". Prólogo a Pilar López García (ed.): El cambio cultural del IV al II milenio en la comarca noroeste de Murcia. CSIC. Madrid: 17-22.

- (1997): "Cómo valorar los sistemas de propiedad a partir de los datos arqueológicos". Trabajos de Prehistoria, 54(2): 81-92.

Gilman Guillén, A. y Thornes, J.B. (1985): El uso de la tierra en la prehistoria del sureste de España. Fundación Juan March. Serie Universitaria. Madrid.

González de Molina, M. y Sevilla Guzmán, E. (1993): "Ecología, campesinado e historia: Para una reinterpretación del desarrollo del Capitalismo en la Agricultu- ra". En E. Sevilla Guzmán y M. González de Molina (eds.): Ecología, Campesinado e Historia. La Piqueta. Madrid: 23-131.

Guidoni, E. (1989): Arquitectura primitiva. Aguilar S.A. Madrid.

Gutiérrez Soler, L. (1998): Poblamiento ibérico en el curso medio del Rio Guadalimar. Microfichas del Servicios de Publicaciones de la Universidad de Jaén.

Gracia, F.; Munilla, G.; García, E.; Playá, R.M. y MuRIEL, S. (1996): "Demografía y superficie de poblamiento en los asentamientos ibéricos del NE. peninsular". En M. ${ }^{a}$ Ángeles Querol y Teresa Chapa (eds.) Homenaje al Profesor Manuel Fernández-Miranda, Complutum Extra, 6 (II): 177-191.

HARRIs, M. (1987): Caníbales y reyes. Los orígenes de las culturas. Alianza. Madrid.

HARrison, R.J. y Moreno LóPEZ, G. (1985): "El policultivo ganadero o la revolución de los productos secundarios". Trabajos de Prehistoria, 42: 51-82.

Hornos Mata, F; Nocete Calvo, F. y Pérez Barea, C. (1987): "Actuación arqueológica de urgencia en yacimiento de lós Pozos en Higuera deArjona (Jaén)".Anuario Arqueológico de Andalucía/1986, III: 193-195.

Hornos Mata, F.; Zafra de la Torre, N.; Castro López, M. (1998): "La gestión de una zona arqueológica urbana: la experiencia de investigación aplicada en Marroquíes Bajos(Jaén)". PH, Boletín del Instituto Andaluz de Patrimonio Histórico 22: 82-91.

Hurtado, V. (1991): "Informe de las excavaciones de urgencia en La Pijotilla. Campaña de 1990", I Jornadas de Prehistoria y Arqueología en Extremadura (19861990). Extremadura Arqueológica II, Mérida-Cáceres: 45-67.

KALB, P. y HöcK, M. (1997): "O povoado fortificado, calcolítico do Monte da Ponte, Évora". En Rodrigo de Balbín y Primitiva Bueno (eds.): II Congreso de arqueología peninsular (Zamora, 1996), II. Fundación Rei Afonso Henriques. Zamora: 417-425.

Laslett, P. y Wall, R. (eds.) 1972: Household and Family in Past Time: Comparative Studies in the Size and Structure of the Domestic Groups. Cambridge University Press. Cambridge.

Laudan, L. (1978): Progress and its Problems. Toward a Theory of Sciencific Growth. University of California Press. Berkeley.

Leduc, C. (1992): “¿Cómo darla en matrimonio?. La Novia en Grecia, siglos IX-IV a.C.”. En Georges Duby y Michele Perrot (dir.): Historia de las mujeres en occidente. 1. Taurus. Madrid: 251-316.

Lizcano Prestel, R.; Gómez del Toro, E.; Cámara Serrano, J.A.; Aguayo, M.; Araque, D.; Bellido, I.; Contreras, I.; Hernández, M.; Izquierdo, M. y Ruiz, J. (1993): " $1^{\mathrm{a}}$ campaña de excavación de urgencia en el pabellón polideportivo de Martos (Jaén)". Anuario Arqueológico de Andalucía /1991, III. Consejería de Cultura de Junta de Andalucía. Cadiz: 375-385. 
Lizcano Prestel, R.; Cámara Serrano, J.A.; Riquelme, J.A.; Cañabate, M.L.; Sánchez Vizcaíno, A. y Afonso, J.A. (1991-1992): "El polideportivo de Martos. Producción económica y símbolos de cohesión en un asentamiento del Neolítico Final en las Campiñas del Alto Guadalquivir". Cuadernos de Prehistoria de la Universidad de Granada, 16-17. 1991-1992: 5-101.

Lorite Mena, J. (1995): Sociedades sin estado. El pensamiento de los otros. Akal. Madrid.

LUMBRERAS, L.G. (1988): "Childe y la tesis de la revolución urbana: la experiencia central andina". En L. Manzanilla (ed): Coloquio V. Gordon Childe. Estudios sobre la revolución neolítica y la revolución urbana. Universidad NacionalAutónoma de México. México: 349-367.

Lull, V. (1983): La “cultura” de ElArgar. Un modelo para el estudio de las formaciones económico-sociales prehistóricas. Akal. Madrid.

MARTÍNEZ LóPEZ, D. (1996): Tierra, herencia y matrimonio. Un modelo sobre la formación de la burguesía agraria andaluza (siglos XVIII-XIX). Servicio de Publicaciones de la Universidad de Jaén. Jaén.

Mederos Martín, A. (1995): “¿Retorno al pasado? Comercio o difusión en los análisis de los Sistemas Mundiales Antiguos". Trabajos de Prehistoria, 52(2): 131-141.

Meillassoux, C. (1987): Mujeres, graneros y capitales. Siglo XXI editores. México.

Molina González, F.; Contreras, F.; Ramos, A.; Mérida, V.; Ortiz, D. y RuIz, V. (1986): "Programa de recuperación del registro arqueológico del Fortín 1 de Los Millares. Análisis preliminar de la organización del espacio". Arqueología Espacial, 8: 175-201. Teruel.

Molina González, F.; NáJera, T. y Aguayo, P. (1979): “La Motilla delAzuer (Daimiel, Ciudad Real). Campaña de 1979". Cuadernos de Prehistoria de la Universidad de Granada, 4: 265-280.

Montero Ruiz, I. y Ruiz Taboada, A. (1996): "Enterramiento colectivo y metalurgia en el yacimiento neolítico del Cerro Virtud (Cuevas de Almanzora, Almería)". Trabajos de Prehistoria, 53(2): 55-75.

Mossé, C. (1983): La femme dans la Gréce antique. A. Michel. París.

Nocete Calvo, N. (1989): El espacio de la coerción. La transición al estado en las Campiñas delAlto Guadalquivir (España). 3000-1500A.C. B.A.R. International Series 492. Tempus Reparatum. Oxford.

Nocete Calvo, N. (1994): La formación del Estado en las Campiñas delAlto Guadalquivir. Universidad de Granada. Granada.

Quesada Quesada, T. (1989): La Serranía de Mágina en la Baja Edad Media. Una tierra fronteriza con el reino nazarí de Granada. Universidad de Granada. Granada.

Ramos Millán, A. (1981): "Interpretaciones secuenciales y culturales de la Edad del Cobre en la zona meridional de la Península Ibérica. La alternativa del materialismo cultural". Cuadernos de Prehistoria de la Universidad de Granada, 6: 242-256.
Ruiz RodríGuEZ, A. (1982): “Jaén desde los primeros pobladores a la Edad de Augusto". En J. Rodríguez (ed.): Historia de Jaén. Diputación Provincial de Jaén. Jaén: 51-111.

- (1989): "La Protohistoria: el $1^{\mathrm{er}}$ milenio A.N.E.”. En J. Fernández (dir.): Jaén, II. Editorial Andalucía. Granada: 401-422.

Ruiz Rodríguez, A.; Nocete Calvo, F. y Sánchez Ruiz, M. (1986): "La Edad del Cobre y la argarización en tierras giennenses". Homenaje a Luis Siret (1934-1984). Consejería de Cultura de la Junta de Andalucía. Sevilla: 271-286.

Ruiz Rodríguez, A. y Molinos Molinos, M. (1993): Los iberos. Análisis arqueológico de un proceso histórico. Crítica. Barcelona.

SAHLINS, M.D. (1972): La economía de la edad de piedra. Akal. Barcelona.

Salvatierra Cuenca, V. (1989): “Cuando Jaén era Yayyan”. En J. Fernández (dir.): Jaén, II. Editorial Andalucía. Granada: 453-490.

Schüle, W. (1986): "El Cerro de la Virgen de la Cabeza, Orce (Granada): consideraciones sobre su marco ecológico y cultural". Homenaje a Luís Siret (1934-1984). Consejería de Cultura de la Junta de Andalucía. Sevilla: 208-220.

Serrano Peña, J.L. y Esteban Marfil, A. (1997): “Intervención arqueológica de urgencia en la calle Llana de San Juan $n^{\circ} 1$ y 3, esquina Santísima Trinidad de Jaén". Anuario Arqueológico de Andalucía/1993. III: 340-345.

Shanin, T. (1983): La clase incómoda. Sociología política del campesinado en una sociedad en desarrollo (Rusia 1910-1925). Alianza Editorial. Madrid.

SHERRATT, A.G. (1981): "Plough and pastoralism: aspects of the secondary products revolution". En I. Hodder, G. Issac and N. Hammond (eds.): Pattern of the past: essays in honour of David Clarke. Cambridge University Press. Cambridge: 261-305.

Stuiver, M. y Reimer, P.J. (1993): "Extended ${ }^{14} \mathrm{C}$ Data Base and Revised CALIB 3.0 ${ }^{14} \mathrm{C}$ Age Calibration Program". Radiocarbon, 35: 215-230.

Vicent García, J.M. (1991): "Fundamentos teórico-metodológicos para un programa de investigación arqueogeográfica". En Pilar López García (ed.): El cambio cultural del IV al II milenio en la comarca noroeste de Murcia. CSIC. Madrid: 29-119.

- (1991b): "El Neolítico, transformaciones sociales y económicas". Boletín de Antropología Americana, 24: 31-61.

Wolf, E.R. (1975): Los campesinos. Editorial Labor. Barcelona.

Zafra de la Torre, N. y Pérez Bareas, C. (1992): "Excavaciones arqueológicas en el Cerro del Alcázar de Baeza. Campaña de 1990. Informe preliminar". Anuario Arqueológico de Andalucía/1990, III: 294-303.

T. P., 56, n. ${ }^{\circ} 1,1999$ 